\title{
Neurology
}

The most widely read and highly cited peer-reviewed neurology journal

The Official Journal of the American Academy of Neurology

\section{Performance of the 2017 and 2010 Revised MicDonald Criteria in Predicting MS Diagnosis After a Clinically I solated Syndrome A MAGNIMS Study}

\section{Author(s):}

Massimo Filippi, MD, FEAN, FAAN $N^{1,2,3,4,5}$; Paolo Preziosa, MD, PhD ${ }^{1,2}$; Alessandro Meani, MSc ${ }^{1}$; Gloria Dalla Costa, MD ${ }^{3,5}$; Sarlota Mesaros, MD, PhD ${ }^{6}$; J elena Drul ovic, MD ${ }^{6}$; Jovana I vanovic, MD ; Alex Rovira, $M^{7}$; Mar Tintorè, MD ${ }^{8}$; Xavier Montal ban, MD ${ }^{8}$; Olga Ciccarelli, MD ${ }^{9}$; Wallace Brownlee, MD ${ }^{9}$; Katherine Miszkie, MD ${ }^{9}$; Christian Enzinger, MD ${ }^{10}$; Michael Khalil, MD, PhD ${ }^{10}$; Frederik Barkhof, MD, PhD ${ }^{11,12}$; Eva M.M. Strijbis, MD, PhD ${ }^{13}$; J etteL Frederiksen, MD, DMSci ${ }^{14}$; Stig P Cramer, MD ${ }^{15}$, 16 ; Enrico Fainardi, $\mathrm{MD}^{17}$; Maria Pia Amato, $\mathrm{MD}^{18}{ }^{19}$; Claudio Gasperini, $\mathrm{MD}^{20}$; Serena Ruggieri, $\mathrm{MD}^{20}$; Vittorio Martinelli, $M^{2}$; Giancarlo Comi, MD ${ }^{5}$; Maria A. Rocca, MD ${ }^{1,2,5}$ on behalf of MAGNIMS Study Group

Neurology ${ }^{\circledR}$ Published A head of Print articles have been peer reviewed and accepted for publication. This manuscript will be published in its final form after copyediting, page composition, and review of proofs. Errors that could affect the content may be corrected during these processes. 


\section{Corresponding Author:}

Massimo Filippi

filippi.massimo@hsr.it

Affiliation Information for All Authors: 1. Neuroimaging Research Unit, Division of Neuroscience, IRCCS San Raffaele Scientific Institute, Milan, Italy; 2. Neurology Unit, IRCCS San RaffaeleScientific Institute, Milan, Italy; 3. Neurorehabilitation Unit IRCCS San Raffaele Scientific Institute, Milan, Italy; 4. Neurophysi ol ogy Service, IRCCS San RaffaeleScientific Institute, Milan, Italy; 5. Vita-Sal ute San Raffaele University, Milan, Italy; 6. Clinic of Neurology, Faculty of Medicine, University of Belgrade, Serbia; 7. Section of Neuroradiology, Department of Radiology, Hospital Universitari Vall d Hebron, Barcelona, Spain; 8. Department of Neurology/Neuroimmunology, MultipleSclerosis Center of Catal onia, Hospital Universitari Vall d Hebron, Barcelona, Spain; 9. NMR Research Unit, Queen Square MS Centre, Department of Neuroinflammation, UCL Institute of Neurology, London, UK; 10. Department of Neurol ogy, Medical University of Graz, Graz, Austria; 11. Department of Radiology and Nuclear Medicine, MS Center Amsterdam, Amsterdam Neuroscience Amsterdam UMC, location VUmc, Amsterdam, The Netherlands; 12. Institutes of Neurology and Heal thcare Engineering, University College London, London, UK; 13. Department of Neurol ogy, MS Center Amsterdam, Amsterdam Neuroscience Amsterdam UMC, location VUmc, Amsterdam, The Netherlands; 14. Clinic of Optic Neuritis and Clinic of Multiple Sclerosis, Department of Neurology, Rigshospital et - Glostrup, University of Copenhagen, Copenhagen, Denmark; 15. Department of Clinical Physiology, Nuclear Medicine and PET, FIU unit, Rigshospital et Gl ostrup, Copenhagen Uni versity Hospital, Copenhagen, Denmark; 16. Department of Clinical Physiology and Nuclear Medicine, Centrefor Functional and Diagnostic Imaging and Research, Hvidovre Hospital, Hvidovre, Denmark; 17. Neuroradiology Unit, Department of Experimental and Clinical Biomedical Sciences 'Mario Serio', University of Florence, Florence, Italy; 18. Department of Neurofarba, University of Florence, Florence, Italy; 19. IRCCS Fondazione Don Carlo Gnocchi, Florence, Italy;20. Department of Neurosciences, San Camillo Forlanini Hospital, Rome, Italy.

\section{Contributions:}

Massimo Filippi: Drafting/revision of the manuscript for content, including medical writing for content; Study concept or design; Analysis or interpretation of data; Additional contributions: Study supervision Paolo Preziosa: Drafting/revision of the manuscript for content, including medical writing for content; Study concept or design; Analysis or interpretation of data

Alessandro Meani: Drafting/revision of the manuscript for content, including medical writing for content; Analysis or interpretation of data; Additional contributions: statistical analysis

Gloria Dalla Costa: Drafting/revisi on of the manuscript for content, including medical writing for content; Major rolein the acquisition of data

Sarlota Mesaros: Drafting/revision of the manuscript for content, including medical writing for content; Major role in the acquisition of data

Jelena Drul ovic: Drafting/revision of the manuscript for content, including medical writing for content; Major rolein the acquisition of data

J ovana I vanovic: Drafting/revision of the manuscript for content, including medical writing for content; Major role in the acquisition of data

Alex Rovira: Drafting/revision of the manuscript for content, including medical writing for content; Major role in the acquisition of data

Mar Tintorè: Drafting/revision of the manuscript for content, including medical writing for content; Major role in the acquisition of data

Xavier Montal ban: Drafting/revision of the manuscript for content, including medical writing for content; Major rolein the acquisition of data

Olga Ciccarelli: Drafting/revision of the manuscript for content, including medical writing for content; Major role in the acquisition of data

Wallace Brownlee: Drafting/revision of the manuscript for content, including medical writing for content; Major rolein the acquisition of data

Katherine Miszkie: Drafting/revision of the manuscript for content, including medical writing for content; Major rolein the acquisition of data

Christian Enzinger: Drafting/revision of the manuscript for content, including medical writing for content; Major rolein the acquisition of data

Michael Khalil: Drafting/revision of the manuscript for content, including medical writing for content; Major role in the acquisition of data

Frederik Barkhof: Drafting/revision of the manuscript for content, including medical writing for content; Major rolein the acquisition of data

Eva M.M. Strijbis: Drafting/revision of the manuscript for content, including medical writing for content; 
Major rolein the acquisition of data

Jette L Frederiksen: Drafting/revision of the manuscript for content, including medical writing for content; Major rolein the acquisition of data

Stig P Cramer: Drafting/revision of the manuscript for content, including medical writing for content; Major role in the acquisition of data

Enrico Fai nardi: Drafting/revision of the manuscript for content, including medical writing for content; Major role in the acquisition of data

Maria Pia Amato: Drafting/revision of the manuscript for content, including medical writing for content;

Major rolein the acquisition of data

Claudio Gasperini: Drafting/revision of the manuscript for content, including medical writing for content;

Major rolein the acquisition of data

Serena Ruggieri: Drafting/revision of the manuscript for content, including medical writing for content; Major role in the acquisition of data

Vittorio Martinelli: Drafting/revision of the manuscript for content, including medical writing for content;

Major rolein the acquisition of data

Giancarlo Comi: Drafting/revision of the manuscript for content, including medical writing for content; Major role in the acquisition of data

Maria A. Rocca: Drafting/revision of the manuscript for content, including medical writing for content; Study concept or design; Analysis or interpretation of data

Number of characters in title: 88

Abstract Word count: 246

Word count of main text: 4357

References: 50

Figures: 5

Tables: 2

Supplemental: Study checklist Supplementary Tables (Table e 1 to Table e-6) and Supplementary Figuree 1 and Supplementary Figure e2

Statistical Analysis performed by: Alessandro Meani, MSc Neuroimaging Research Unit, Division of Neuroscience, IRCCS San Raffaele Scientific Institute, Milan, Italy

Serch Terms: [ 41 ] Multiplesclerosis, [ 120 ] MRI, [ 322 ] Class II

Acknowledgements: The funding sources had no role in study design, collection, analysis, and interpretation of data; writing of the report; or the decision to submit the paper for publication. Prof Ciccarelli is a NIHR Research Professor. Prof Ciccarelli and Prof Barkhof receive funding from the NIHR UCLH Biomedical Research Centre.

Study Funding: Prof Ciccarelli and Prof Barkhof receivefunding from the NIHR UCLH Biomedical Research Centre.

Disdosures: Theauthors declare that they have no competing interests in relation to this work. Potential conflicts of interest outside the submitted work are as follows: M. Filippi is Editor-in-Chief of the J ournal of Neurology and Associate Editor of Human Brain Mapping, received compensation for consulting services and/or speaking activities from Almiral, Alexion, Bayer, Biogen, Celgene, Eli Lilly, Genzyme, Merck-Serono, Novartis, Roche, Sanofi, Takeda, and Teva Pharmaceutical Industries, and receives research support from Biogen I dec, Merck-Serono, Novartis, Roche, Teva Pharmaceutical Industries, Italian Ministry of Health, Fondazione Italiana Sclerosi Multipla, and ARiSLA (FondazioneItaliana di Ricerca per la SLA); P. Preziosa received speaker honoraria from Biogen I dec, Novartis, Merck Serono and ExceMED; A. Meani declared no competing interests; G. Dall la Costa declared no competing interests; S. Mesaros has received travel funding from Merck, Bayer Schering, Medis, and GenzymeSanofi; has received honoraria for speaking from Merck Serono and Novartis; and has al so received research grant support from the Ministry of Education and Science, Republic of Serbia (project 175031); J. Drul ovic declare no competing interests; J. I vanovic declared no competing interests; A. Rovira has received a speaker honorarium from Bayer, Sanofi-Genzyme, Bracco, 
Merck-Serono, Teva Pharmaceutical Industries Ltd., Novartis, Roche, and Biogen. Heserves on scientific advisory boards for Novartis, Sanofi-Genzyme, SyntheticMR, Roche, Biogen, and OLEA Medical; M. Tintoré has received compensation for consulting services and speaking honoraria from Almirall, Bayer Schering Pharma, Biogen-Idec, Excemed, Jansen, Genzyme, Merck-Serono, Novartis, Roche, Sanofi-Aventis, Viela Bio and Teva Pharmaceuticals. She is co-editor of MultipleSclerosis J ournal-ETC; X. Montal ban has received a speaker honorarium and travel expenses for participation in scientific meetings or advisory boards in past years from Actelion, Alexion, Bayer, Biogen, Celgene, EMD Serono, Genzyme, Medday, Merck, Nervgen, Novartis, Roche, Sanofi-Genzyme, Teva Pharmaceuticals, TG Therapeutics, Excemed, MSIF, and NMSS; O. Ciccarelli receives grant support from the UK MS Society, National MS Society, NIHR, EU-H2020, Spinal Cord Research Foundation, Rosetrees Trust, Progressive MS Alliance, Bioclinica AND GE Neuro. She is a consultant for Novartis, Teva, Roche, Biogen, and Merck-Serono. She is an Associate Editor of Neurology, for which she receives and honorarium; W. Brownlee declared no competing interests; K. Miszkiel declared no competing interests; C. Enzinger reports personal fees from Biogen, Bayer Schering, Merck Serono, Novartis, Shire, Genzyme, and Teva/Sanofi-Aventis, and Roche; and grants from Merck Serono, Biogen, and Teva/Sanofi-Aventis, outside the submitted work; M. Khalil has received funding for travel and speaker honoraria from Bayer, Novartis, Merck, Biogen I dec and Teva Pharmaceutical Industries Ltd. and serves on scientific advisory boards for Biogen I dec, Merck Serono, Roche, Novartis, Bristol-Myers Squi bb and Gilead. He received research grants fromTeva Pharmaceutical Industries, Ltd., Biogen and Novartis, F. Barkhof acts as a consultant to Biogen-Idec, J anssen, Bayer, Merck, Roche, Novartis, Genzyme, and Apitope Ltd; hehas received sponsorship fromEU-H2020, Nederlands Wetenschappelijk Onderzoek, SMSR, EU-FP7, Teva, Novartis, and Biogen; E.M.M. Strijbis declared no competing interests; J .L. Frederiksen reported personal fees from Almirall, Biogen, Genzyme, Merck Serono, Novartis, Sanofi-Aventis, Teva, and Takeda, outside of the submitted work; S. Cramer reports personal fees from Biogen, Genzyme, Merck Serono, and Roche; and grants fromBiogen, outside the submitted work; E. Fai nardi declared no compeing interests; M.P. A mato reported receiving grants and personal fees from Merck, Biogen, Sanofi Genzyme, Roche, Teva, and Novartis outside the submitted work; C. Gasperini has received fees as invited speaker or travel expenses for attending meeting from Biogen, Merck-Serono, Teva, Sanofi, Novartis, Genzyme; S. Ruggieri has received fees as invited speaker or travel expenses for attending meeting from Biogen, Merck-Serono, Novartis; V. Martinelli has received speaker's honoraria from Biogen, Merck Serono, Bayer Schering, Teva, and Sanofi Aventis; G. Comi has received compensation for consulting services for Novartis, Teva, Sanofi, Genzyme, Merck, Biogen, Excemed, Roche, Almirall, Chugai, Receptos, and Forward Pharma; and compensation for speeking activities for Novartis, Teva, Sanofi, Genzyme, Merck, Biogen, Excemed, and Roche; M.A. Rocca received speakers honoraria from Bayer, Biogen, Bristol Myers Squibb, Celgene, Genzyme, Merck Serono, Novartis, Roche, and Teva, and receives research support from the MS Sociely of Canada and Fondazione Italiana Sclerosi Multipla.

\section{Abstract}

Background and Objective. To compare the performance of the 2017 revisions to the McDonald criteria with the 2010 McDonald criteria in establishing MS diagnosis and predicting prognosis in patients with clinically isolated syndrome (CIS) suggestive of multiple sclerosis (MS).

Methools. CSF examination, brain and spinal cord MRI obtained $\leq 5$ months from CIS onset, and a follow-up brain MRI acquired within 15 months from CIS onset were eval uated in $785 \mathrm{CIS}$ patients from 9 European centers. Date of second clinical attack and of reaching Expanded Disability Status Score (EDSS) $\geq 3.0$, if they occurred, were al so collected. Performance of the 2017 and 2010 McDonald criteria for dissemination in space (DIS), time (DIT) (including oligoclonal bands assessment) and DIS+DIT for predicting a second clinical attack (clinically definite [CD] 
MS) and EDSS $\geq 3.0$ at follow-up was eval uated. Time to MS diagnosis for the different criteria was also estimated.

Results. At follow-up (median=69.1 months), 406/785 CIS patients developed CDMS. At 36 months, the 2017 DIS+DIT criteria had higher sensitivity ( 0.83 vs 0.66 ), lower specificity ( 0.39 vs 0.60 ) and si milar area under the curve val ues ( 0.61 vs 0.63 ). Median time to MS diagnosis was shorter with the 2017 vs the 2010 or CDMS criteria (2017 revision=3.2; 2010 revision=13.0; $\mathrm{CDMS}=58.5$ months). The two sets of criteria similarly predicted EDSS $\geq 3.0$ milestone. Three periventricular lesions improved specificity in patients $\geq 45$ years.

Discussion. The 2017 McDonald criteria showed higher sensitivity, lower specificity and similar accuracy in predicting CDMS compared to 2010 McDonald criteria, while shortening time to diagnosis of MS.

Classification of Evidence. This study provides Class II evidence that the 2017 McDonald Criteria more accurately distinguish CDMS in patients early after a CIS when compared to the 2010 McDonald criteria. 


\section{Introduction}

In 2001, MRI was formally included in the criteria for multiple sclerosis (MS) diagnosis to demonstrate dissemination in space (DIS) and time (DIT) of MS lesions. ${ }^{1}$ Subsequent iterations of the McDonald criteria ${ }^{2,3}$ have simplified MS diagnosis, while maintaining sensitivity, specificity and accuracy. The McDonald criteria shorten the time from onset of symptoms to MS diagnosis in patients with a clinically isolated syndrome (CIS) suggestive of MS, without waiting for the occurrence of a second clinical event ${ }^{4}$ This is crucial since an increasing number of therapies have been demonstrated to be effective in favorably modifying MS disease course especially if started early. ${ }^{5}$

Recently, new evidence regarding the utility of MRI and CSF analysis for MS diagnosis has become avail lable. The MAGNIMS network proposed modified MRI criteria for DIS in $2016 .{ }^{6}$ The performance of these evidence-based recommendation was eval uated in a large multicenter MAGNIMS study ${ }^{7}$ that informed the 2017 revisions to MS diagnostic criteria, ${ }^{8}$ including removing the distinction between symptomatic and asymptomatic lesions and combining cortical and juxtacortical lesions in DIS (data avail lable from Dryad: Table e-1 https://doi.org/10.5281/zenodo.5566178). Additionally, in CIS patients fulfilling DIS criteria, the presence of CSF-specific oligocl onal bands (OCBs) allows a diagnosis of MS, in the absence of clinical or MRI evidence of DIT (data available from Dryad: Table e1 https://doi.org/10.5281/zenodo.5566178). ${ }^{8}$ An additional modification proposed by the MAGNIMS network ${ }^{6}$ to improve the criteria specificity, ${ }^{7}$ but not included in the 2017 revisions, was to increase the number of lesions needed to establ ish periventricular involvement from one to three.

After their publication, several studies compared the performance of the 2017 and 2010 revisions to the McDonald criteria in adult ${ }^{9-14}$ and pediatric CIS patients. ${ }^{15-17}$ Globally, they showed that the 2017 McDonald criteria have higher sensitivity but lower specificity compared with the 2010 criteria in predicting clinically definite (CD) MS, but a shorter time to MS diagnosis. 
Several aspects related to the performance of the 2017 revision of the McDonald criteria still need to be fully eval uated. The performance of these criteria has mainly been assessed in small, monocentric cohorts of CIS patients. Different outcomes have been used, including the estimation of CDMS after a relatively short or heterogeneous follow-up, or by combining clinical (CDMS) with MRI (new lesions) status. Additionally, some important aspects have been only partially explored. These include the influence of age and CIS topography on criteria performance, and the impact of treatment initiation on the risk of developing CDMS. Finally, the ability of the 2017 revisions to predict disability accumulation has not been investigated yet.

To clarify all these important aspects, we compared the performance of the 2017 McDonald criteria in predicting CDMS development and MS prognosis, and in enabling an earlier MS diagnosis, with that of the 2010 McDonald criteria, in a large multicenter study of patients with a typical CIS suggestive of MS. The influence of type of $\mathrm{CIS}$ onset and increasing the number of periventricular lesions needed to demonstrate DIS from one to three (which might have a different relevance according to age at onset) was al so eval uated.

\section{Methods}

Standard Protocol Approvals, Registrations, and Patient Consents. Approval was received from the institutional ethical standards committee on human experimentation of each participating center for any experiments using human subjects. Written informed consent was obtained from all patients participating in the study at the time of data acquisition.

Primary Research Question and Classification of Evidence. Primary research question: in patients with a typical CIS suggestive of MS, do the 2017 revision to the MCDonald criteria outperform the 2010 McDonald criteria for the diagnosis of MS?

This study provides Class II evidence that the 2017 McDonald Criteria more accurately distinguish CDMS in patients early after a CIS when compared to the 2010 McDonald criteria. 
Patients. This project was run within the European MAGNIMS network (http://www.magnims.eu/) and involved nine highly specialized MS centers, which were: a) the Neuroimaging Research Unit and Department of Neurology, San Raffaele Scientific Institute, Milan, Italy; b) MS Centre Amsterdam, VU University Medical Centre, the Netherlands; c) the Centre d'Esclerosi Múltiple de Catal unya (Cemcat), the Department of Neurology/Neuroimmunology and the Section of Neuroradiology, Department of Radiology, Hospital Universitari Vall d'Hebron, Universitat Autònoma de Barcel ona, Barcelona, Spain; d) the Clinics of Neurology and Radiology, Faculty of Medicine, University of Belgrade, Belgrade, Serbia; e) the Department of Neurology, Rigshospitalet Glostrup and University of Copenhagen, Copenhagen, Denmark; f) the Department of Neurology, Medical University of Graz, Graz, Austria; g) the Queen Square MS Centre, University College London (UCL) Institute of Neurology, London, UK; h) the Department of Neurosciences, San Camillo-Forlanini Hospital, Rome, Italy; i) the Department NEUROFARBA, University of Florence, Florence, Italy/IRCCS Fondazione Don Carlo Gnocchi, Florence, Italy.

The study design was similar to that of previous studies ai med at assessing the performance of MS diagnostic criteria. ${ }^{7,18}$

Centers identified $\mathrm{CIS}$ patients recruited into local prospective clinical and MRI follow-up studies from J une 1995 to October 2020 with: a) age between 18 and 60 years; b) a diagnosis of CIS suggestive of $\mathrm{MS} ;{ }^{19} \mathrm{C}$ ) a typical clinical presentation of relapse-onset $\mathrm{MS} ;{ }^{20} \mathrm{~d}$ ) a complete neurol ogical examination, with scoring of the Expanded Disability Status Scale (EDSS), performed within 5 months from the clinical onset; e) baseline brain and spinal cord MRI scans obtained within 5 months from the clinical onset; f) a follow-up brain MRI obtained $\leq 15$ months from CIS onset. Development of CDMS was defined as the occurrence of a second clinical event attributable to demyelination lasting more than 24 hours and after an interval $\geq 1$ month from the first attack, with evidence of two separate lesions. Time to CDMS was cal culated as the interval between the first two clinical events. 
The foll owing information was collected: age at CIS onset, sex, presence of CSF-specific OCBs (where avai lable), date and topography of CIS onset, dates of the second event and of last avail able follow-up, date of reaching EDSS $\geq 3.0$, date of initiation and type of disease-modifying treatment (DMT), dates of MRI scans and field strengths of the scanners used.

MRI analysis and CSF examination. For the brain, axial dual-echo (DE) and/or fast fluidattenuated inversion recovery (FLAIR) and post-contrast $(0.1 \mathrm{mmol} / \mathrm{kg}$ of gadol inium [Gd]-DTPA; acquisition delay: $\approx 10$ minutes) T1-weighted sequences were acquired at baseline and at follow-up. Slice thickness varied between 3 and $5 \mathrm{~mm}$, in-plane resolution between 0.45 and $1.0 \mathrm{~mm}$, no gap between slices. A brain double inversion recovery (DIR) sequence was available for 337/785 (42.9\%) CIS patients from three centres (Barcelona, Belgrade and Milan). For the spinal cord, sagittal short tau inversion recovery (STIR) and/or T2-weighted and post-contrast T1-weighted sequences ( $0.1 \mathrm{mmol} / \mathrm{kg}$ of gadolinium [Gd]-DTPA; acquisition delay: 5 minutes) with $3 \mathrm{~mm}$ slice thickness, in-plane resolution between 0.4375 and $1.0 \mathrm{~mm}$, no gap between slices, covering the cervical and thoracic cord were acquired. For 120/785 (15.3\%) CIS patients, baselineSC involvement was established using avail able MRI reports, due to missing or corrupted raw MRI data.

All images were assessed by consensus by two experienced observers (PP and MAR), blinded to the patients' identity and MS status at the Neuroimaging Research Unit (Milan, Italy). Brain white matter (WM) lesions were identified on dual-echo/FLAIR images and were defined as hyperintensities involving at least 3 voxels, present on at least two slices and visible on two different sequences (eg., FLAIR and T2 or proton density and T2). Spinal cord lesions were identified on sagittal short tau inversion recovery (STIR) and/or T2-weighted sequences. Total number of WM lesions, number of periventricular (abutting the lateral ventricles without intervening WM), juxtacortical (touching the cortex), cortical (within the cortex), posterior fossa (located in the brainstem, cerebellar peduncles and cerebellar hemispheres) and spinal cord lesions were eval uated following published recommendations. ${ }^{21}$ Cortical lesions and juxtacortical lesions 
identified from double inversion recovery (avail able in 337/785 [43\%]) and T2 and FLAIR sequences were combined. ${ }^{8} \mathrm{Gd}$-enhancing lesions (area of hyperintensity on post-contrast T1weighted images) ${ }^{21}$ were identified on post-contrast T1-weighted scans.

On the MRI scan acquired at follow-up, the numbers of new T2-hyperintense and Gdenhancing lesions were quantified.

OCBs were eval uated in 670/785 (85\%) CIS patients in the CSF and serum at the time of baseline clinical evaluation by agarose isoelectric focusing combined with immunoblotting. When bands were present only in the CSF, they were considered CSF-specific.

DIS and DIT criteria. The $2010^{3}$ and $2017^{8}$ McDonald DIS criteria were assessed on baseline MRI scans, whereas the $2010^{3}$ and $2017^{8}$ McDonald DIT criteria were defined on baseline and follow-up MRI and according to CSF-specific OCB status (data available from Dryad: Tablee-1 https://doi.org/10.5281/zenodo.5566178). Although presence of OCBs does not reflect DIT, but is an alternative to DIT, we used the definition of DIT including OCBs. The fulfilment of DIS plus DIT criteria for both the 2010 and 2017 was al so assessed.

The performance of the 2017 McDonal d criteria ${ }^{8}$ was eval uated al so without OCB assessment.

As additional analyses, we compared the performances of 2017 and 2010 McDonald criteria according to the type of CIS at onset (i.e, optic neuritis, brainstem/cerebellar syndrome, or spinal cord syndrome). The performance in CIS patients with a hemispheric or multifocal onset was not eval uable due to their limited number. Finally, we eval uated criteria performance using three instead of one periventricular lesions to define periventricular involvement, according to age at onset ( $<25,25-34,35-44$, and $\geq 45$ years).

Statistical analysis. Cumulative/dynamic timedependent receiver operating characteristic (ROC) curve analysis ${ }^{22}$ for censored survival data was applied to assess the performance of the MRI criteria for DIS, DIT and DIS plus DIT (al so without OCB assessment), using the clinical status (CDMS or CIS) over time as outcome. Sensitivity, specificity, accuracy, positive and negative 
predictive values at months 36 and 60 were cal cul ated. Bias-corrected and accelerated bootstrap method ${ }^{23}$ was used to estimate $95 \%$ confidence intervals (Cls). A nal yses were repeated after excluding all CIS patients receiving DMT before the second clinical event.

The cumulative risk of CDMS development from the first clinical event to the last available follow-up was represented using Kaplan-Meier survival curves (patients censored according to their follow-up). Extended Cox regression model s using time to CDMS as the outcome and adjusted for age (continuous), sex (binary), treatment (binary, timedependent, i.e, treatment effects were modeled considering the time when a patient started any treatment [thus considering two conditions: without or under treatment]), and disease onset type (optic neuritis, brainster/cerebellar, spinal cord, hemispheric, multifocal ), were performed to obtain adjusted hazard ratios (aHRs) and 95\% Cls. A shared gamma-frailty term was al so included to address center effects, accounting for unobserved heterogeneity and statistical dependence between clustered time to-event data. ${ }^{24}$ The possible interactions between MRI criteria and treatment or type of onset were explored by estimating similar models including a specific interaction term

Similar models were al so estimated using time to reach EDSS $\geq 3.0$ as the outcome

Median time to MS diagnosis according to different criteria (i.e, 2017 or 2010 McDonald criteria or CDMS) were estimated using Kaplan-Meier survival curves.

Data Availability. The corresponding author had full access to all the data in the study and takes responsi bility for the integrity of the data and the accuracy of the data analysis. The anonymized dataset used and analyzed during the current study are avail lable from the corresponding author on reasonable request.

\section{Results}

Demographic, clinical and MRI data. From 958 CIS patients, the final cohort comprised 785 CIS patients fulfilling inclusion criteria. Figure 1 shows study flow chart and Table 1 summarizes the main baseline demographic, clinical and MRI findings of these patients. 
Seven hundred and forty-five out of 785 (95\%) CIS patients had a monofocal onset, including optic neuritis in 286/745 (38\%), a brainstem/cerebellar syndrome in 169/745 (23\%), a spinal cord syndrome in 239/745 (32\%) and a hemispheric syndrome in 51/745 (7\%).

At the last evaluation (median=69.1 months; IQR=39.8-112.1), 406/785 (52\%) CIS patients had experienced a second clinical episode (median time to conversion $=13.2$ months, IQR $=5.2-$ 31.5), and 101/785 (13\%) CIS patients reached an EDSS $\geq 3.0 ; 437 / 785$ (56\%) CIS patients started DMTs (235 after the first clinical episode; 202 after the second): 141 (32\%) of them did not develop CDMS.

At baseline, 78/785 (10\%) CIS patients had a normal brain MRI (24 [31\%] of whom had an abnormal spinal cord MRI), and 398/785 (51\%) had normal spinal cord MRI (346 [87\%] of whom had an abnormal brain MRI). CSF-specific OCBs were found in 459/670 (69\%) CIS patients.

At follow-up MRI 386/785 (79\%) patients devel oped new T2-hyperintense or Gd-enhancing lesions.

Performances of different sets of criteria. For DIS at month 36, the 2017 McDonald criteria had higher sensitivity $(0.86[95 \% \mathrm{Cl}=0.82-0.90]$ vs $0.78[95 \% \mathrm{Cl}=0.73-0.82])$, lower specificity ( 0.32 [95\% $\mathrm{Cl}=0.28-0.37]$ vs 0.38 [95\% $\mathrm{Cl}=0.33-0.43]$ ), and similar area under the curve (AUC) values $(0.59$ [ $95 \% \mathrm{Cl}=0.56-0.62]$ vs $0.58[95 \% \mathrm{Cl}=0.55-0.62])$ than the $2010 \mathrm{McD}$ onald criteria, for predicting CDMS (Table2, Figure 2).

For DIT at month 36, the 2017 vs 2010 McDonald criteria showed higher sensitivity ( 0.95 [95\% $\mathrm{Cl}=0.92-0.97]$ vs $0.77[95 \% \mathrm{Cl}=0.72-0.82])$, lower specificity $(0.20[95 \% \mathrm{Cl}=0.16-0.25]$ vs $0.53[95 \% \mathrm{Cl}=0.47-0.58])]$ and slightly lower AUC values $(0.58[95 \% \mathrm{Cl}=0.55-0.60]$ vs $0.65[95 \%$ $\mathrm{Cl}=0.61-0.68]$ ) for predicting CDMS (Table 2).

For DIS plus DIT at month 36, the 2017 McDonald criteria had higher sensitivity (0.83 [95\% $\mathrm{Cl}=0.79-0.87]$ vs $0.66[95 \% \mathrm{Cl}=0.61-0.71])$, lower specificity $(0.39[95 \% \mathrm{Cl}=0.34-0.44]$ vs 0.60 [95\% $\mathrm{Cl}=0.55-0.65])$, and similar AUC values $(0.61[95 \% \mathrm{Cl}=0.58-0.64]$ vs $0.63[95 \% \mathrm{Cl}=0.59$ 0.67]) (Table2, Figure2). 
The eval uation at month 36 of the 2017 McDonald criteria without CSF-specific OCB assessment decreased sensitivity $(0.74[95 \% \mathrm{Cl}=0.69-0.78])$, increased specificity $(0.54$ [ $95 \%$ $\mathrm{Cl}=0.49-0.59])$ and preserved AUC values $(0.64$ [95\% $\mathrm{Cl}=0.60-0.67])$ (Table 2, Figure 2).

At month 60, the performance of the 2017 and 2010 McDonald criteria were comparable to what observed at month 36 (Table 2).

The analysis evaluating DIS, DIT and DIS plus DIT in CIS patients not receiving DMT before the second clinical event ( $n=550$ ) showed, for both sets of criteria, a slight decrease in sensitivity together with increased specificity and AUC values, with the 2017 McDonal d criteria showing a higher sensitivity, a lower specificity and similar AUC val ues compared to the 2010 McDonald criteria (data avai lable from Dryad: Table e-2 https://doi.org/10.5281/zenodo.5566178).

For DIS plus DIT, the 2017 vs 2010 McDonal d criteria showed higher sensitivity, lower specificity and similar AUC values in CIS patients presenting with optic neuritis (Figure 3, data avail able from Dryad: Table e-3 https://doi.org/10.5281/zenodo.5566178). In CIS patients with brainstem/cerebellar syndromes, the 2017 vs 2010 McDonald criteria for DIS and DIS plus DIT had higher AUC values. Although these differences were more evident at month 36 than at month 60 , overall accuracy of the 2017 vs 2010 McDonald criteria was constantly superior over time (Figure 3, data avai lable from Dryad: Table e-3 https://doi.org/10.5281/zenodo.5566178). Finally, in CIS patients with a spinal cord syndrome, the 2017 vs 2010 McDonald criteria for DIS plus DIT had lower AUC values (Figure 3, data avail lable from Dryad: Table e3 https://doi.org/10.5281/zenodo.5566178).

When assessing diagnostic criteria performance according to age groups at M36, the 2017 modified DIS criteria with 3 instead of 1 periventricular lesions resulted in slightly lower sensitivity (0.76 [95\% $\mathrm{Cl}=0.57-0.89]$ vs 0.79 [95\% $\mathrm{Cl}=0.6-0.91])$, but improved specificity $(0.32$ [95\% $\mathrm{Cl}=0.19-0.46]$ vs $0.18[95 \% \mathrm{Cl}=0.08-0.32])$ and accuracy $(0.54[95 \% \mathrm{Cl}=0.44-0.63]$ vs $0.49[95 \%$ $\mathrm{Cl}=0.40-0.57]$ ) in CIS patients aged $\geq 45$ years (Figure 4, data available from Dryad: Table e-4 https://doi.org/10.5281/zenodo.5566178). These results were confirmed when considering CDMS at 
month 60 as the outcome, although these differences were marginal for DIS plus DIT (data available from Dryad: Figure e1, Tablee-4 https://doi.org/10.5281/zenodo.5566178).

Prediction of CDMS and EDSS $\geq 3.0$. Although the cumulative risk of CDMS development was similar for the different sets of criteria, the lack of fulfilment of the 2017 McDonald criteria was associated with a higher risk of non-converting to CDMS when compared to the 2010 McDonald criteria (Figure 2, Table 2, data avail able from Dryad: Table $e-5$ https://doi.org/10.5281/zenodo.5566178). The adjusted hazard ratios (aHRs) were higher for the 2017 compared with the 2010 McDonald criteria, for DIS only ( $\mathrm{aHR}=3.25[95 \% \mathrm{Cl}=2.43-4.34]$ and $2.45[95 \% \mathrm{Cl}=1.91-3.15]$ ) and for DIS plus DIT (aHR=3.59 [95\% Cl=2.71-4.76] and 2.68 [95\% $\mathrm{Cl}=2.15-3.35])$.

The aHRs of both sets of criteria were not affected by disease onset type, whereas the interaction between the different criteria and treatment status was statistically significant ( $\mathrm{p}$ ranging from $\varangle 0.001$ to 0.009 ), with aHRs being lower under vs without treatment (data avail able from Dryad: Tablee-5 https://doi.org/10.5281/zenodo.5566178).

Cumulative risk of reaching EDSS $\_3.0$ and aHRs were similar for both sets of criteria (data avail able from Dryad: Figure e-2, Table e-6 https://doi.org/10.5281/zenodo.5566178).

Timeto MS diagnosis. The median time to MS diagnosis was shorter with the 2017 compared with the 2010 McDonald and CDMS criteria (2017 McDonal d criteria=3.2 months [ $95 \% \mathrm{Cl}=3.0$ 3.7]; 2017 McDonal d criteria without OCBs=11.4 months [95\% Cl=7.3-12.7]; 2010 McDonald criteria $=13.0$ months $[95 \% \mathrm{Cl}=12.0-14.5]$; $\mathrm{CDMS}=58.5$ months [95\% $\mathrm{Cl}=49.6-76.0]$ ) (Figure 5).

\section{Discussion}

By eval uating a large, multicenter cohort of patients with typical $\mathrm{CIS},{ }^{8}$ our study demonstrated that the 2017 McDonald criteria had higher sensitivity, lower specificity and overall similar accuracy in predicting conversion to CDMS than the 2010 McDonald criteria. This validation study extends previous studies, ${ }^{9-12,14}$ which are characterized by high between-study 
variability performance of the different criteria, possibly due to the heterogeneity in the demographic and clinical characteristics of the patients eval uated, the MRI protocols used to define MRI criteria, lengths of the follow-ups, statistical approaches used and the influence of treatment.

We confirmed that the inclusion of OCB assessment ${ }^{25}$ increased the sensitivity, reducing the specificity, while preserving the accuracy of the criteria. The decreased specificity derived from OCB evaluations, not done in all cases but requested according to local protocols, could raise some concerns regarding the risk of MS overdiagnosis. ${ }^{26}$ Our analysis al so showed that although the performance of the 2017 McDonald criteria seems slightly worse in the short term than the 2010 McDonald criteria, due to a lower specificity, the overall accuracy increases over time, thus the presence of OCBs contributes to correctly identify patients developing CDMS when longer followup are considered, underlying the relevance of I onger eval uation to better eval uate the performance of the diagnostic criteria. The progressive improvement of criteria performance with time could be due to the effects of DMTs that, if started, may delay the occurrence of a second event, thus negatively influencing the specificity of the criteria when the follow-up is limited to a few years.

The performance of the 2017 and 2010 McDonald criteria was similar in CIS patients with optic neuritis. This is expected, al so considering the limited relevance in distinguishing symptomatic from asymptomatic lesions in patients with optic neuritis, with the slight differences mainly due to the inclusion of OCB assessment. Accordingly, the evaluation of optic nerve invol vement could improve the diagnostic accuracy in this type of onset. ${ }^{6,7,27,28}$

Interestingly, considering especially the pointwise eval uation at month 36 more than that at month 60, and the overall accuracy over time, it seems clear that, compared to the 2010 McDonald criteria, the 2017 McDonal d criteria showed a better performance in predicting CDMS development in CIS patients with a brainstem/cerebellar syndrome. The inclusion of infratentorial lesions irrespective of being symptomatic in patients with this type of $\mathrm{CIS}$ allows to capture the contribution of the infratentorial site, which is known to be clinically relevant, in respect to CDMS development ${ }^{29,} 30$ and MS prognosis. ${ }^{31,32}$ In CIS patients with a spinal cord syndrome, the 2017 
McDonald criteria had higher sensitivity, lower specificity and slightly lower accuracy than the 2010 McDonald criteria. This may seem counterintuitive, since the presence of spinal cord lesions facilitates MS diagnosis and predicts CDMS conversion as well as disability accumulation. ${ }^{33,34} \mathrm{~A}$ previous study showed that the presence of spinal cord lesions hel ped in predicting CDMS particularly in CIS patients presenting with a non-spinal symptomatology, with the highest risk (up to 14.4 times) found in patients who did not fulfill brain DIS criteria. ${ }^{34}$

Periventricular lesions increase with age, especially in subjects with cerebrovascular risk factors ${ }^{35}$ and occur in several neurological conditions characterized by WM lesions and mimicking MS, including small-vessel disease, ${ }^{36}$ and migrai ne ${ }^{37-39}$ In previous studies the requirement for three periventricular lesions improved specificity of the $2010^{7,40,41}$ and $2017^{12}$ McDonald criteria for DIS, especially in older CIS patients. ${ }^{41}$ Additionally, a threshold of three or more periventricular lesions was found to be one of the most accurate predictors of CDMS conversion. ${ }^{29,42,43}$ In line with this, we found that three periventricular lesions improved the specificity and accuracy of the 2017 McDonald DIS criteria, but slightly reduced sensitivity, especially in CIS patients aged $\geq 45$ years. The main aim of the subsequent iterations of the McDonald criteria is to allow an earlier and more accurate MS diagnosis in people who present with a CIS, but it remains essential to reduce the risk of misdiagnosis due to a combination of increased sensitivity and reduced specificity, i.e. an oversimplification of MS criteria. ${ }^{26}$ Among the proposed modifications, the eval uation of three periventricular lesions appears easily implementable in the clinical setting and may present a distinctive criterion to improve the specificity and the accuracy of the diagnostic criteria at least in older CIS patients who do not not satisfy DIT criteria - as suggested by a previous study ${ }^{-41}$ and/or patients with comorbidities.

Survival analyses showed that the cumulative risk of CDMS development was similar in CIS patients fulfilling the criteria independently from the set of criteria investigated. Conversely, $\mathrm{ClS}$ patients who did not fulfil the 2017 McDonald criteria had a higher risk of not devel oping CDMS than patients who met the criteria. These findings, combined with those of a previous study, ${ }^{9}$ 
suggest that the 2017 MCDonal d criteria could be useful to identify CIS patients at low risk of developing a second relapse.

Of note, the significant interaction found between the different criteria and treatment status, with lower aHR found under treatment, further confirms that the use DMTs worsens the performance of the criteria and can explain, at least in part, differences in the performances of the criteria compared with previous reports. ${ }^{18,40,44,45}$ This hypothesis is al so confirmed by the sensitivity analyses performed excluding all CIS patients starting a DMT before the occurrence of a second clinical event that showed an improvement of the specificity of both the 2017 and 2010 revisions of the McDonald criteria compared to the analyses who eval uated the whole cohort of $\mathrm{CIS}$ patients included in the study.

Regarding the prognostic value for disability accumulation, survival probability analyses showed that CIS patients fulfilling either the 2010 or the 2017 McDonal d criteria had a significantly higher risk to reach an EDSS $\geq 3.0$ than patients who did not meet the criteria, and that the two sets of criteria had similar performance, with a slight superiority of the 2017 McDonald criteria. This is in line with previous studie ${ }^{45}$ and supports the relevance of infratentorial, ${ }^{31,32}$ spinal cord ${ }^{33,34,46}$ and Gd-enhancing lesions ${ }^{46}$ but also of CSF-specific $\mathrm{OCBS}^{47-49}$ as relevant predictors of clinical disability.

Finally, consistent with previous studies ${ }^{9-11,13,50}$ our results confirmed that, with the 2017 MCDonald criteria, more CIS patients reached a diagnosis of MS al ready after the first clinical manifestation, with a single MRI scan. In our study, the 2017 McDonald criteria shortened the median time to MS diagnosis by 4.6 years compared with the clinical criterion al one and by 10 months compared with the $2010 \mathrm{McD}$ onald criteria. This has substantial implications in the management of $\mathrm{CIS}$ patients. An earlier MS diagnosis may facilitate earlier treatment, with beneficial effects on MS prognosis, since therapies have demonstrated to reduce the risk of CDMS conversion roughly by 30-55\% and could exert long-term benefits to CIS patients. \{Forster, 2019 5\} Further studies are still needed to demonstrate that treatment start after clinical onset instead of 
waiting until a second clinical relapse may al so positively limit long-term disability progression. ${ }^{5}$ Clearly, this aspect could be negatively counterbal anced by the risk of misdiagnosis. ${ }^{26}$ It should be noted that the apparent lower specificity of the 2017 McDonald criteria could reflect earlier treatment with a lower chance of developing DIT - calling into question the appropriateness of the CDMS outcome. It should be al so noted that, al though quite lower at month 36 , specificity of the 2017 revisions of the McDonald criteria increased at month 60 (0.46) and further improved at month 120 (0.53), approaching that of the 2010 McDonald criteria (0.62), but still remaining lower.

Nevertheless, the 2017 McDonald criteria must be applied in the right context, after the exclusion of differential diagnoses, in patients who present with symptoms and signs which are typical of $\mathrm{MS}^{26}$ and with the proper assessment of lesions on MRI. ${ }^{21}$ In fact, a lower specificity may determine a higher preval ence of MS misdiagnosis and unnecessary initiation of DMT may be associated with unnecessary risks and morbidity in misdiagnosed patients. ${ }^{26}$

This study has some limitations. First, the analyses have been performed retrospectively. Despite this, all CIS patients included are part of ongoing prospective studies performed by each participating center all lowing us to have long foll ow-up to better investigate the performance of the different sets of criteria. Second, CIS patients were collected from highly specialized centers, thus possibly selecting patients with higher lesion number and risk of CDMS conversion (52\% in our cohort). However, the multicenter setting with MRI exams acquired with both 1.5 and 3.0 Tesla and different sequence parameters, al lowed us to eval uate the MRI criteria in a cohort of CIS patients that should be representative of the European clinical scenario. Third, cortical Iesion and OCB assessment were not available for all patients. However, cortical lesion eval uation was found to not significantly contribute to DIS criteria performance, ${ }^{7}$ whereas OCB assessment was missing only in a minority (2.2\%) of CIS patients not fulfilling DIT criteria. Fourth, no formal statistical testing have been performed between the performances of the 2017 and 2010 revisions to the McDonald criteria and no adj ustment for multiplicity was applied. Accordingly, our observations - particularly 
the sub-group analyses - should be regarded as expl oratory and require replication in an independent dataset.

Overall, this study confirms that the 2017 McDonald criteria have higher sensitivity, lower specificity and overall similar accuracy compared with the 2010 McDonald criteria in predicting CDMS development independently from the type of clinical onset. These criteria simplify the clinical use of MRI criteria without reducing accuracy and al low an earlier diagnosis of MS. Three periventricular lesions should be considered in future revisions of the McDonal d criteria to improve the specificity and the accuracy in ol der CIS patients. 


\section{Appendix 1 Authors}

\begin{tabular}{|c|c|c|}
\hline Name & Location & Contribution \\
\hline Massimo Filippi, MD & $\begin{array}{l}\text { San Raffaele Scientific Institute, } \\
\text { Vita-Salute San Raffaele } \\
\text { University, Milan, Italy }\end{array}$ & $\begin{array}{l}\text { study concept, analysis and } \\
\text { interpretation of the data, } \\
\text { drafting/revising the } \\
\text { manuscript He al so acted as } \\
\text { study supervisor. }\end{array}$ \\
\hline $\begin{array}{l}\text { Paolo Preziosa, MD, } \\
\text { PhD }\end{array}$ & $\begin{array}{l}\text { San Raffaele Scientific Institute, } \\
\text { Milan, Italy }\end{array}$ & $\begin{array}{l}\text { study concept, analysis and } \\
\text { interpretation of the data, } \\
\text { drafting/revising the } \\
\text { manuscript. }\end{array}$ \\
\hline $\begin{array}{l}\text { Alessandro Meani, } \\
\text { MsC }\end{array}$ & $\begin{array}{l}\text { San Raffaele Scientific Institute, } \\
\text { Milan, Italy }\end{array}$ & $\begin{array}{l}\text { analysis and interpretation of } \\
\text { the data, statistical anal ysis, and } \\
\text { drafting/revising the } \\
\text { manuscript. }\end{array}$ \\
\hline $\begin{array}{l}\text { Gloria Dalla Costa, } \\
\text { MD }\end{array}$ & $\begin{array}{l}\text { San Raffaele Scientific Institute, } \\
\text { Vita-Salute San Raffaele } \\
\text { University, Milan, Italy }\end{array}$ & $\begin{array}{l}\text { acquisition of the data and } \\
\text { drafting/revising the manuscript }\end{array}$ \\
\hline $\begin{array}{l}\text { Sarlota Mesaros, MD, } \\
\text { PhD }\end{array}$ & $\begin{array}{l}\text { University of Belgrade, Belgrade, } \\
\text { Serbia }\end{array}$ & $\begin{array}{l}\text { acquisition of the data and } \\
\text { drafting/revising the manuscript }\end{array}$ \\
\hline Jelena Drul ovic, MD & $\begin{array}{l}\text { University of Belgrade, Belgrade, } \\
\text { Serbia }\end{array}$ & $\begin{array}{l}\text { acquisition of the data and } \\
\text { drafting/revising the manuscript }\end{array}$ \\
\hline J ovana I vanovic, MD & $\begin{array}{l}\text { University of Belgrade, Belgrade, } \\
\text { Serbia }\end{array}$ & $\begin{array}{l}\text { acquisition of the data and } \\
\text { drafting/revising the manuscript }\end{array}$ \\
\hline Alex Rovira, MD & $\begin{array}{l}\text { Hospital Universitari Vall } \\
\text { d'Hebron, Barcelona, Spain }\end{array}$ & $\begin{array}{l}\text { acquisition of the data and } \\
\text { drafting/revising the manuscript }\end{array}$ \\
\hline Mar Tintorè, MD & $\begin{array}{l}\text { Hospital Universitari Vall } \\
\text { d'Hebron, Barcelona, Spain }\end{array}$ & $\begin{array}{l}\text { acqui sition of the data and } \\
\text { drafting/revising the manuscript }\end{array}$ \\
\hline Xavier Montal ban, MD & $\begin{array}{l}\text { Hospital Universitari Vall } \\
\text { d'Hebron, Barcelona, Spain }\end{array}$ & $\begin{array}{l}\text { acquisition of the data and } \\
\text { drafting/revising the manuscript }\end{array}$ \\
\hline Olga Ciccarelli, MD & $\begin{array}{l}\text { UCL Institute of Neurol ogy, } \\
\text { London, UK }\end{array}$ & $\begin{array}{l}\text { acquisition of the data and } \\
\text { drafting/revising the manuscript }\end{array}$ \\
\hline $\begin{array}{l}\text { Wallace Brownlee, } \\
\text { MD }\end{array}$ & $\begin{array}{l}\text { UCL Institute of Neurology, } \\
\text { London, UK }\end{array}$ & $\begin{array}{l}\text { acquisition of the data and } \\
\text { drafting/revising the manuscript }\end{array}$ \\
\hline $\begin{array}{l}\text { Katherine Miszkie, } \\
\text { MD }\end{array}$ & $\begin{array}{l}\text { UCL Institute of Neurol ogy, } \\
\text { London, UK }\end{array}$ & $\begin{array}{l}\text { acquisition of the data and } \\
\text { drafting/revising the manuscript }\end{array}$ \\
\hline $\begin{array}{l}\text { Christian Enzinger, } \\
\text { MD }\end{array}$ & $\begin{array}{l}\text { Medical University of Graz, Graz, } \\
\text { Austria }\end{array}$ & $\begin{array}{l}\text { acquisition of the data and } \\
\text { drafting/revising the manuscript }\end{array}$ \\
\hline $\begin{array}{l}\text { Michael Khalil, MD, } \\
\text { PhD }\end{array}$ & $\begin{array}{l}\text { Medical University of Graz, Graz, } \\
\text { Austria }\end{array}$ & $\begin{array}{l}\text { acquisition of the data and } \\
\text { drafting/revising the manuscript }\end{array}$ \\
\hline $\begin{array}{l}\text { Frederik Barkhof, MD, } \\
\text { PhD }\end{array}$ & $\begin{array}{l}\text { AmsterdamUMC, location VUmc, } \\
\text { Amsterdam, The Netherlands; } \\
\text { University College London, } \\
\text { London, UK. }\end{array}$ & $\begin{array}{l}\text { acqui sition of the data and } \\
\text { drafting/revising the manuscript }\end{array}$ \\
\hline $\begin{array}{l}\text { Eva M.M. Strijbis, } \\
\text { MD, PhD }\end{array}$ & $\begin{array}{l}\text { AmsterdamUMC, location VUmC, } \\
\text { Amsterdam, The Netherlands }\end{array}$ & $\begin{array}{l}\text { acquisition of the data and } \\
\text { drafting/revising the manuscript }\end{array}$ \\
\hline $\begin{array}{l}\text { JetteL. Frederiksen, } \\
\text { MD, DMSci }\end{array}$ & $\begin{array}{l}\text { Rigshospitalet - Glostrup, } \\
\text { University of Copenhagen, } \\
\text { Denmark }\end{array}$ & $\begin{array}{l}\text { acquisition of the data and } \\
\text { drafting/revising the manuscript }\end{array}$ \\
\hline Stig Cramer, MD & $\begin{array}{l}\text { Rigshospitalet Glostrup, } \\
\text { Copenhagen University Hospital; }\end{array}$ & $\begin{array}{l}\text { acqui sition of the data and } \\
\text { drafting/revising the manuscript }\end{array}$ \\
\hline
\end{tabular}




\begin{tabular}{|l|l|l|}
\hline & $\begin{array}{l}\text { Hvidovre Hospital, Hvidovre, } \\
\text { Denmark. }\end{array}$ & \\
\hline Enrico Fai nardi, MD & $\begin{array}{l}\text { University of Florence, Florence, } \\
\text { Italy }\end{array}$ & $\begin{array}{l}\text { acquisition of the data and } \\
\text { drafting/revising the manuscript }\end{array}$ \\
\hline Maria Pia Amato, MD & $\begin{array}{l}\text { University of Florence, Florence, } \\
\text { Italy; IRCCS Fondazione Don } \\
\text { Carlo Gnocchi, Florence, Italy }\end{array}$ & $\begin{array}{l}\text { acquisition of the data and } \\
\text { drafting/revising the manuscript }\end{array}$ \\
\hline Claudio Gasperini, MD & $\begin{array}{l}\text { San Camillo Forlanini Hospital, } \\
\text { Rome, Italy }\end{array}$ & $\begin{array}{l}\text { acquisition of the data and } \\
\text { drafting/revising the manuscript }\end{array}$ \\
\hline Serena Ruggieri, MD & $\begin{array}{l}\text { San Camillo Forlanini Hospital, } \\
\text { Rome, Italy }\end{array}$ & $\begin{array}{l}\text { acqui sition of the data and } \\
\text { drafting/revising the manuscript }\end{array}$ \\
\hline $\begin{array}{l}\text { Vittorio Martinelli, } \\
\text { MD }\end{array}$ & $\begin{array}{l}\text { San RaffaeleScientific Institute, } \\
\text { Milan, Italy }\end{array}$ & $\begin{array}{l}\text { acquisition of the data and } \\
\text { drafting/revising the manuscript }\end{array}$ \\
\hline Giancarlo Comi, MD & $\begin{array}{l}\text { VitaSalute San Raffaele } \\
\text { University, Milan, Italy }\end{array}$ & $\begin{array}{l}\text { acquisition of the data and } \\
\text { drafting/revising the manuscript }\end{array}$ \\
\hline Maria A. Rocca, MD & $\begin{array}{l}\text { San RaffaeleScientific Institute, } \\
\text { Vita-Salute San Raffaele } \\
\text { University, Milan, Italy }\end{array}$ & $\begin{array}{l}\text { study concept, analysis and } \\
\text { interpretation of the data, } \\
\text { drafting/revising the } \\
\text { manuscript }\end{array}$ \\
\hline
\end{tabular}




\section{Appendix 2 Coinvestigators}

\begin{tabular}{|l|l|l|l|}
\hline Name & Location & Role & Contribution \\
\hline Nicola DeStefano, MD & $\begin{array}{l}\text { University of Siena, Siena, } \\
\text { Italy }\end{array}$ & Co-investigator & $\begin{array}{l}\text { Study design and } \\
\text { interpretation of the data }\end{array}$ \\
\hline Jacqueline Palace, MD & $\begin{array}{l}\text { University of Oxford, } \\
\text { Oxford, UK }\end{array}$ & Co-investigator & $\begin{array}{l}\text { Study design and } \\
\text { interpretation of the data }\end{array}$ \\
\hline Ludwig Kappos, MD & $\begin{array}{l}\text { University of Basel, Basel, } \\
\text { Switzerland }\end{array}$ & Co-investigator & $\begin{array}{l}\text { Study design and } \\
\text { interpretation of the data }\end{array}$ \\
\hline Jaume Sastre-Garriga, MD & $\begin{array}{l}\text { Hospital Universitari Vall } \\
\text { d'Hebron, Universitat } \\
\text { Autònoma de Barcelona, } \\
\text { Barcelona, Spain }\end{array}$ & Co-investigator & $\begin{array}{l}\text { Study design and } \\
\text { interpretation of the data }\end{array}$ \\
\hline Tarek Y ousry, MD & $\begin{array}{l}\text { Queen Square MS Centre, } \\
\text { UCL Institute of } \\
\text { Neurol ogy, London, UK }\end{array}$ & Co-investigator & $\begin{array}{l}\text { Study design and } \\
\text { interpretation of the data }\end{array}$ \\
\hline
\end{tabular}




\section{References}

1. McDonald WI, Compston A, Edan G, et al. Recommended diagnostic criteria for multiple sclerosis: guidelines from the International Panel on the diagnosis of multiple sclerosis. Ann Neurol 2001;50:121-127.

2. Polman $\mathrm{CH}$, Reingold SC, Edan G, et al. Diagnostic criteria for multiple sclerosis: 2005 revisions to the "McDonald Criteria". Ann Neurol 2005;58:840-846.

3. Polman CH, Reingold SC, Banwell B, et al. Diagnostic criteria for multiple sclerosis: 2010 revisions to the McDonal d criteria. Ann Neurol 2011;69:292-302.

4. Brownlee WJ, Swanton JK, Altmann DR, Ciccarelli O, Miller DH. Earlier and more frequent diagnosis of multiple sclerosis using the McDonald criteria. J Neurol Neurosurg Psychiatry 2015;86:584-585.

5. Forster M, Graf J, Mares J, Aktas O, Hartung HP, Kremer D. Drug Treatment of Clinically Isolated Syndrome. CNS Drugs 2019;33:659-676.

6. Filippi M, Rocca MA, Ciccarelli O, et al. MRI criteria for the diagnosis of multiple sclerosis: MAGNIMS consensus guidelines. The Lancet Neurology 2016;15:292-303.

7. Filippi M, Preziosa P, Meani A, et al. Prediction of a multiple sclerosis diagnosis in patients with clinically isolated syndrome using the 2016 MAGNIMS and 2010 McDonald criteria: a retrospective study. The Lancet Neurology 2018;17:133-142.

8. Thompson AJ, Banwell BL, Barkhof F, et al. Diagnosis of multiple sclerosis: 2017 revisions of the McDonal d criteria. The Lancet Neurol ogy 2018;17:162-173.

9. van der Vuurst de Vries RM, MescheriakovaJY, Wong YY M, et al. Application of the 2017 Revised McDonald Criteria for Multiple Sclerosis to Patients With a Typical Clinically Isolated Syndrome. JAMA Neurol 2018;75:1392-1398.

10. Hyun JW, Kim W, Huh SY, et al. A pplication of the 2017 McDonald diagnostic criteria for multiple sclerosis in Korean patients with clinically isolated syndrome. Mult Scler 2019;25:14881495.

11. Habek M, Pavicic T, Ruska B, et al. Establishing the diagnosis of multiple sclerosis in Croatian patients with clinically isolated syndrome: 2010 versus 2017 McDonald criteria. Mult Scler Relat Disord 2018;25:99-103.

12. Miclea A, Salmen A, Wiest R, et al. Prediction of conversion to multiple sclerosis using the 2017 McDonald and 2016 MAGNIMS criteria in patients with clinically isolated syndrome: a retrospective single-centre study. Ther Adv Neurol Disord 2019;12:1756286419835652.

13. LeeDH, Peschke M, Ut KS, Linker RA. Diagnostic value of the 2017 McDonald criteria in patients with a first demyelinating event suggestive of relapsing-remitting multiple sclerosis. Eur J Neurol 2019;26:540-545.

14. Souissi A, Mrabet S, Nasri A, et al. Multiple sclerosis 2017 McDonald criteria are also relevant for Tunisians. Mult Scler Relat Disord 2020;43:102161.

15. Fadda G, Brown RA, Longoni G, et al. MRI and laboratory features and the performance of international criteria in the diagnosis of multiple sclerosis in children and adolescents: a prospective cohort study. Lancet Child Adolesc Heal th 2018;2:191-204.

16. Hacohen Y, Brownlee W, Mankad K, et al. Improved performance of the 2017 McDonald criteria for diagnosis of multiple sclerosis in children in a real-life cohort. Mult Scler 2020;26:13721380.

17. Wong YYM, de Mol CL, van der Vuurst de Vries RM, et al. Real-world validation of the 2017 McDonald criteria for pediatric MS. Neurol Neuroimmunol Neuroinflamm 2019;6:e528.

18. Swanton JK, Rovira A, Tintore M, et al. MRI criteria for multiple sclerosis in patients presenting with clinically isolated syndromes: a multicentre retrospective study. The Lancet Neurology 2007;6:677-686. 
19. Miller D, Barkhof F, Montal ban X, Thompson A, Filippi M. Clinically isolated syndromes suggestive of multiple sclerosis, part I: natural history, pathogenesis, diagnosis, and prognosis. The Lancet Neurology 2005;4:281-288.

20. Brownlee WJ, Hardy TA, Fazekas F, Miller DH. Diagnosis of multiple sclerosis: progress and challenges. Lancet 2017;389:1336-1346.

21. Filippi M, Preziosa $\mathrm{P}$, Banwell $\mathrm{BL}$, et al. Assessment of lesions on magnetic resonance imaging in multiple sclerosis: practical guidelines. Brain 2019;142:1858-1875.

22. Hung $\mathrm{H}$, Chiang $\mathrm{C}$. Estimation models for timedependent AUC with survival data. Canadian J ournal of Statistics 2010;38:8-26.

23. Efron B. Better Bootstrap Confidence Intervals. Journal of the American Statistical Association 1987;82:171-185.

24. Glidden DV, Vittinghoff E. Modelling clustered survival data from multicentre clinical trials. Stat Med 2004;23:369-388.

25. Arrambide G, Tintore M, Espejo C, et al. The value of oligoclonal bands in the multiple sclerosis diagnostic criteria. Brain 2018;141:1075-1084.

26. Solomon AJ, Naismith RT, Cross AH. Misdiagnosis of multiple sclerosis: Impact of the 2017 McDonal d criteria on clinical practice. Neurol ogy 2019;92:26-33.

27. Brownlee WJ, Miszkiel KA, Tur C, Barkhof F, Miller DH, Ciccarelli O. Inclusion of optic nerve involvement in dissemination in space criteria for multiple sclerosis. Neurology 2018;91:el130-el134.

28. Vidal-J ordana A, Rovira A, Arrambide G, et al. Optic Nerve Topography in Multiple Sclerosis Diagnosis: The Utility of Visual Evoked Potentials. Neurol ogy 2021;96:e482-e490.

29. Barkhof F, Filippi M, Miller DH, et al. Comparison of MRI criteria at first presentation to predict conversion to clinically definite multiple sclerosis. Brain 1997;120 ( Pt 11):2059-2069.

30. Filippi M, Rocca MA, Calabrese M, et al. Intracortical lesions: relevance for new MRI diagnostic criteria for multiple sclerosis. Neurology 2010;75:1988-1994.

31. Minneboo A, Barkhof F, Polman CH, Uitdehaag BM, Knol DL, Castelijns JA. Infratentorial lesions predict long-term disability in patients with initial findings suggestive of multiple sclerosis. Arch Neurol 2004;61:217-221.

32. Tintore M, Rovira A, Arrambide G, et al. Brainstem lesions in clinically isolated syndromes. Neurology 2010;75:1933-1938.

33. Arrambide G, Rovira A, Sastre-Garriga J, et al. Spinal cord lesions: A modest contributor to diagnosis in clinically isolated syndromes but a relevant prognostic factor. Mult Scler 2018;24:301312 .

34. Sombekke MH, Wattjes MP, Balk LJ, et al. Spinal cord lesions in patients with clinically isolated syndrome: a powerful tool in diagnosis and prognosis. Neurology 2013;80:69-75.

35. Nyquist PA, Bilgel M, Gottesman R, et al. Age differences in periventricular and deep white matter lesions. Neurobiol Aging 2015;36:1653-1658.

36. Del Brutto OH, Mera RM, Costa AF, Silva P, Del Brutto VJ. Dawson Fingers in Older Adults with Cerebral Small Vessel Disease: A Population Study. Eur Neurol 2020;83:421-425.

37. Absinta M, Rocca MA, Colombo B, et al. Patients with migraine do not have MRI-visible cortical lesions. Journal of neurology 2012;259:2695-2698.

38. Lapucci C, Saitta L, Bommarito G, et al. How much do periventricular lesions assist in distinguishing migraine with aura from CIS? Neurology 2019;92:e1739-el744.

39. Liu S, Kullnat J, Bourdette $D$, et al. Prevalence of brain magnetic resonance imaging meeting Barkhof and McDonald criteria for dissemination in space among headache patients. Mult Scler 2013;19:1101-1105.

40. Brownlee WJ, Miszkiel KA, Altmann DR, Ciccarelli O, Miller DH. Periventricular lesions and MS diagnostic criteria in young adults with typical clinically isolated syndromes. Mult Scler 2017;23:1031-1034. 
41. Arrambide $G$, Tintore $M$, Auger $C$, et al. Lesion topographies in multiple sclerosis diagnosis: A reappraisal. Neurology 2017;89:2351-2356.

42. Ruet A, Deloire MS, Ouallet JC, Molinier S, Brochet B. Predictive factors for multiple sclerosis in patients with clinically isolated spinal cord syndrome. Mult Scler 2011;17:312-318.

43. Ruet A, Arrambide G, Brochet B, et al. Early predictors of multiple sclerosis after a typical clinically isolated syndrome. Mult Scler 2014;20:1721-1726.

44. Brownlee WJ, Swanton JK, Miszkiel KA, Miller DH, Ciccarelli O. Should the symptomatic region be included in dissemination in space in MRI criteria for MS? Neurology 2016;87:680-683.

45. Tintore M, Otero-Romero S, Rio J, et al. Contribution of the symptomatic lesion in establishing MS diagnosis and prognosis. Neurology 2016;87:1368-1374.

46. Brownlee WJ, Altmann DR, Prados F, et al. Early imaging predictors of long-term outcomes in relapse-onset multiplesclerosis. Brain 2019;142:2276-2287.

47. Dobson R, Ramagopalan S, Davis A, Giovannoni G. Cerebrospinal fluid oligoclonal bands in multiple sclerosis and clinically isol ated syndromes: a meta-analysis of preval ence, prognosis and effect of latitude J Neurol Neurosurg Psychiatry 2013;84:909-914.

48. Tintore M, Rovira A, Rio J, et al. Defining high, medium and low impact prognostic factors for developing multiple sclerosis. Brain 2015;138:1863-1874.

49. Kuhle J, Disanto G, Dobson R, et al. Conversion from clinically isolated syndrome to multiple sclerosis: A large multicentre study. Mult Scler 2015;21:1013-1024.

50. Gaetani L, Prosperini L, Mancini A, et al. 2017 revisions of McDonald criteria shorten the time to diagnosis of multiple sclerosis in clinically isolated syndromes. Journal of neurology 2018;265:2684-2687. 
Table 1. Main baseline demographic, clinical, and MRI findings from the final cohort of CIS patients.

\begin{tabular}{|c|c|c|}
\hline & & $\begin{array}{l}\text { All cases } \\
(n=785)\end{array}$ \\
\hline Demographic & ical data & \\
\hline Number (\%) of & & \\
\hline Men/Won & & $255(32 \%) / 530$ (68\%) \\
\hline Median age at c & QR) [years] & $32.0(26.0-39.0)$ \\
\hline Median timesir & et at baseline MRI (IQR) [months] & $1.9(0.8-3.0)$ \\
\hline Median EDSS & ne (IQR) & $1.5(1.0-2.0)$ \\
\hline Clinical present & ptom(s) (\%): & \\
\hline Monofocal & & $745(95 \%)$ \\
\hline - Optic neurit & & • $286 / 745$ (38\%) \\
\hline -Brainstem/c & ir syndrome & •169/745 (23\%) \\
\hline -Spinal cord & & •239/745 (32\%) \\
\hline -Hemispheric & & • 51/745 (7\%) \\
\hline Multifocal & & $40(5 \%)$ \\
\hline Number $(\%)$ of & With CSF analysis & $670(85 \%)$ \\
\hline patients & With OCBs & $459 / 670(69 \%)$ \\
\hline & Receiving treatment at FU & 437 (56\%) \\
\hline & - After the first clinical episode & •235/437 (54\%) \\
\hline & - After the second clinical episode & • 202/437 (46\%) \\
\hline & CDMS at FU (\%) & 406 (52\%) \\
\hline Median time to & in converters (IQR) [months] & $13.3(5.2-31.5)$ \\
\hline Median FU dur & all patients (IQR) [months] & $69.1(39.8-112.1)$ \\
\hline Median FU dur & non-converters (IQR) [months] & $54.0(34.0-86.5)$ \\
\hline Number $(\%)$ of & 5 reaching EDSS $\geq 3.0$ at FU & $101(13 \%)$ \\
\hline MRI data & & \\
\hline MRI field stren & $: 1.5 \mathrm{~T} / 3.0 \mathrm{~T}$ & 645 (82\%) / 140 (18\%) \\
\hline Baseline numbe & f patients with lesions [brain and cord] & 731 (93\%) \\
\hline Number (\%) of & 5 with DIR & $337(43 \%)$ \\
\hline Median lesion r & (IQR) [brain and cord] & $9(3-19)$ \\
\hline
\end{tabular}




\begin{tabular}{|l|l|l|}
\hline \multicolumn{2}{|l|}{ Median timeto FU MRI (IQR) [months] } & $12.1(7.7-14.3)$ \\
\hline \multicolumn{2}{|l|}{ MRI criteria } & $590(75 \%)$ \\
\hline $\begin{array}{l}\text { Baseline number (\%) } \\
\text { of patients with }\end{array}$ & $\geq 1$ PV lesion & $502(64 \%)$ \\
\cline { 2 - 3 } & $\geq 1 \mathrm{JC}$ lesion & $116 / 337(34 \%)$ \\
\cline { 2 - 3 } & $\geq 1 \mathrm{CL}$ & $519(66 \%)$ \\
\cline { 2 - 3 } & $\geq 1 \mathrm{CL} / \mathrm{JC}$ & $358(46 \%)$ \\
\cline { 2 - 3 } & $\geq 1 \mathrm{PF}$ lesion & $387(49 \%)$ \\
\cline { 2 - 3 } & $\geq 1 \mathrm{SC}$ lesion & $320(41 \%)$ \\
\cline { 2 - 3 } & $\geq 1 \mathrm{Gd}$-enhancing lesion & $386(49 \%)$ \\
\hline \multirow{2}{*}{$\begin{array}{l}\text { Number (\%) of patients with } \geq 1 \text { new T2/Gd-enhancing lesion at } \\
\text { FU MRI }\end{array}$}
\end{tabular}

Abbreviations: CDMS=clinically definite multiple sclerosis; CIS=clinically isolated syndrome; $\mathrm{CL}=$ cortical lesion; $\mathrm{CSF}=$ cerebrospinal fluid; DIR=double inversion recovery; EDSS=Expanded Disability Status Scale; FU=follow-up; Gd=gadolinium; IQR=interquartile range; JC=juxtacortical; $\mathrm{MRI}=$ magnetic resonance imaging; $\mathrm{OCBs=0ligocl} \mathrm{onal} \mathrm{bands;} \mathrm{PF=posterior} \mathrm{fossa;}$

$\mathrm{PV}=$ periventricular; SC=spinal cord; $\mathrm{T}=$ tesla. 
Table2 Performance of the different combined MRI criteria for DIS, DIT and DIS plus DIT al so according to the eval uation of OCBs for development of CDMS in the final cohort ( $n=785)$ at 36 and 60 months' follow-up.

\begin{tabular}{|c|c|c|c|c|c|c|}
\hline Criteria & Timepoint & $\begin{array}{l}\text { Sensitivity } \\
(95 \% \mathrm{CI})\end{array}$ & $\begin{array}{l}\text { Specificity } \\
\text { (95\% CI) }\end{array}$ & $\begin{array}{l}\text { AUC } \\
(95 \% \mathrm{CI})\end{array}$ & $\begin{array}{l}\text { PPV } \\
(95 \% \mathrm{CI})\end{array}$ & $\begin{array}{l}\text { NPV } \\
(95 \% \mathrm{CI})\end{array}$ \\
\hline \multicolumn{7}{|l|}{ DIS only } \\
\hline \multirow{2}{*}{2010 MCDonald ${ }^{3}$} & M36 & $\begin{array}{l}0.78 \\
(0.73-0.82)\end{array}$ & $\begin{array}{l}0.38 \\
(0.33-0.43)\end{array}$ & $\begin{array}{l}0.58 \\
(0.55-0.62)\end{array}$ & $\begin{array}{l}0.48 \\
(0.44-0.53)\end{array}$ & $\begin{array}{l}0.70 \\
(0.64-0.76)\end{array}$ \\
\hline & M60 & $\begin{array}{l}0.78 \\
(0.74-0.82)\end{array}$ & $\begin{array}{l}0.47 \\
(0.40-0.53)\end{array}$ & $\begin{array}{l}0.62 \\
(0.58-0.66)\end{array}$ & $\begin{array}{l}0.60 \\
(0.55-0.65)\end{array}$ & $\begin{array}{l}0.67 \\
(0.61-0.73)\end{array}$ \\
\hline \multirow{2}{*}{2017 McDonald ${ }^{8}$} & M36 & $\begin{array}{l}0.86 \\
(0.82-0.90)\end{array}$ & $\begin{array}{l}0.32 \\
(0.28-0.37)\end{array}$ & $\begin{array}{l}0.59 \\
(0.56-0.62)\end{array}$ & $\begin{array}{l}0.49 \\
(0.44-0.53)\end{array}$ & $\begin{array}{l}0.76 \\
(0.69-0.82)\end{array}$ \\
\hline & M60 & $\begin{array}{l}0.85 \\
(0.81-0.88)\end{array}$ & $\begin{array}{l}0.38 \\
(0.31-0.45)\end{array}$ & $\begin{array}{l}0.61 \\
(0.58-0.65)\end{array}$ & $\begin{array}{l}0.59 \\
(0.54-0.63)\end{array}$ & $\begin{array}{l}0.71 \\
(0.64-0.78)\end{array}$ \\
\hline \multicolumn{7}{|l|}{ DIT only } \\
\hline \multirow{2}{*}{2010 McDonald ${ }^{3}$} & M36 & $\begin{array}{l}0.77 \\
(0.72-0.82)\end{array}$ & $\begin{array}{l}0.53 \\
(0.47-0.58)\end{array}$ & $\begin{array}{l}0.65 \\
(0.61-0.68)\end{array}$ & $\begin{array}{l}0.55 \\
(0.50-0.59)\end{array}$ & $\begin{array}{l}0.76 \\
(0.71-0.81)\end{array}$ \\
\hline & M60 & $\begin{array}{l}0.75 \\
(0.71-0.80)\end{array}$ & $\begin{array}{l}0.59 \\
(0.52-0.65)\end{array}$ & $\begin{array}{l}0.67 \\
(0.63-0.71)\end{array}$ & $\begin{array}{l}0.65 \\
(0.6-0.7)\end{array}$ & $\begin{array}{l}0.70 \\
(0.64-0.75)\end{array}$ \\
\hline 2017 MCDonald ${ }^{\beta}$ & M36 & $\begin{array}{l}0.95 \\
(0.92-0.97)\end{array}$ & $\begin{array}{l}0.20 \\
(0.16-0.25)\end{array}$ & $\begin{array}{l}0.58 \\
(0.55-0.60)\end{array}$ & $\begin{array}{l}0.48 \\
(0.44-0.52)\end{array}$ & $\begin{array}{l}0.83 \\
(0.75-0.90)\end{array}$ \\
\hline
\end{tabular}




\begin{tabular}{|c|c|c|c|c|c|c|}
\hline & M60 & $\begin{array}{l}0.94 \\
(0.91-0.97)\end{array}$ & \begin{tabular}{|l|}
0.28 \\
$(0.22-0.35)$
\end{tabular} & \begin{tabular}{|l|}
0.61 \\
$(0.58-0.65)$
\end{tabular} & \begin{tabular}{|l|}
0.59 \\
$(0.54-0.63)$
\end{tabular} & \begin{tabular}{|l|}
0.82 \\
$(0.73-0.89)$
\end{tabular} \\
\hline \multirow{2}{*}{2017 MCDonald without OCBs ${ }^{8}$} & M36 & $\begin{array}{l}0.80 \\
(0.76-0.85)\end{array}$ & $\begin{array}{l}0.47 \\
(0.41-0.52)\end{array}$ & \begin{tabular}{|l}
0.63 \\
$(0.60-0.67)$
\end{tabular} & \begin{tabular}{|l}
0.53 \\
$(0.48-0.57)$
\end{tabular} & $\begin{array}{l}0.76 \\
(0.71-0.81)\end{array}$ \\
\hline & M60 & $\begin{array}{l}0.79 \\
(0.75-0.84)\end{array}$ & $\begin{array}{l}0.53 \\
(0.46-0.60)\end{array}$ & \begin{tabular}{|l}
0.66 \\
$(0.62-0.70)$
\end{tabular} & \begin{tabular}{|l}
0.64 \\
$(0.58-0.68)$
\end{tabular} & $\begin{array}{l}0.71 \\
(0.65-0.77)\end{array}$ \\
\hline \multicolumn{7}{|l|}{ DIS plusDIT } \\
\hline \multirow{2}{*}{2010 McDonald 3} & M36 & $\begin{array}{l}0.66 \\
(0.61-0.71)\end{array}$ & \begin{tabular}{|l}
0.60 \\
$(0.55-0.65)$
\end{tabular} & \begin{tabular}{|l|}
0.63 \\
$(0.59-0.67)$
\end{tabular} & \begin{tabular}{|l}
0.55 \\
$(0.50-0.60)$
\end{tabular} & \begin{tabular}{|l}
0.71 \\
$(0.66-0.75)$
\end{tabular} \\
\hline & M60 & $\begin{array}{l}0.65 \\
(0.59-0.69)\end{array}$ & $\begin{array}{l}0.66 \\
(0.59-0.72)\end{array}$ & $\begin{array}{l}0.65 \\
(0.61-0.69)\end{array}$ & \begin{tabular}{|l}
0.66 \\
$(0.60-0.72)$
\end{tabular} & $\begin{array}{l}0.64 \\
(0.59-0.69)\end{array}$ \\
\hline \multirow{2}{*}{2017 MCDonald ${ }^{\beta}$} & M36 & $\begin{array}{l}0.83 \\
(0.79-0.87)\end{array}$ & $\begin{array}{l}0.39 \\
(0.34-0.44)\end{array}$ & \begin{tabular}{|l}
0.61 \\
$(0.58-0.64)$
\end{tabular} & \begin{tabular}{|l}
0.51 \\
$(0.46-0.55)$
\end{tabular} & $\begin{array}{l}0.76 \\
(0.70-0.81)\end{array}$ \\
\hline & M60 & $\begin{array}{l}0.82 \\
(0.78-0.86)\end{array}$ & \begin{tabular}{|l}
0.46 \\
$(0.40-0.53)$
\end{tabular} & \begin{tabular}{|l}
0.64 \\
$(0.60-0.68)$
\end{tabular} & \begin{tabular}{|l}
0.61 \\
$(0.56-0.66)$
\end{tabular} & $\begin{array}{l}0.71 \\
(0.65-0.77)\end{array}$ \\
\hline \multirow{2}{*}{2017 MCDonald without OCBs ${ }^{8}$} & M36 & $\begin{array}{l}0.74 \\
(0.69-0.78)\end{array}$ & \begin{tabular}{|l}
0.54 \\
$(0.49-0.59)$
\end{tabular} & \begin{tabular}{|l}
0.64 \\
$(0.60-0.67)$
\end{tabular} & \begin{tabular}{|l}
0.54 \\
$(0.49-0.59)$
\end{tabular} & $\begin{array}{l}0.73 \\
(0.68-0.78)\end{array}$ \\
\hline & M60 & $\begin{array}{l}0.72 \\
(0.67-0.76)\end{array}$ & \begin{tabular}{|l}
0.59 \\
$(0.53-0.66)$
\end{tabular} & \begin{tabular}{|l}
0.66 \\
$(0.62-0.70)$
\end{tabular} & \begin{tabular}{|l}
0.65 \\
$(0.59-0.7)$
\end{tabular} & $\begin{array}{l}0.67 \\
(0.61-0.73)\end{array}$ \\
\hline
\end{tabular}


Abbreviations: $A U C=$ area under the curve; CDMS=clinically definite MS; CI=confidence interval; DIS=dissemination in space; $\mathrm{DIT}=$ dissemination in time; $M=$ month; $M R I=$ magnetic resonance imaging; $N P V=$ negative predictive value; OCBs=oligoclonal bands; PPV=positive predictive val ue 


\section{Figure legends}

Figure 1. Study flow chart. See text for further details. Abbreviations: CIS=clinically isolated syndrome; $\mathrm{MRI}=$ magnetic resonance imaging.

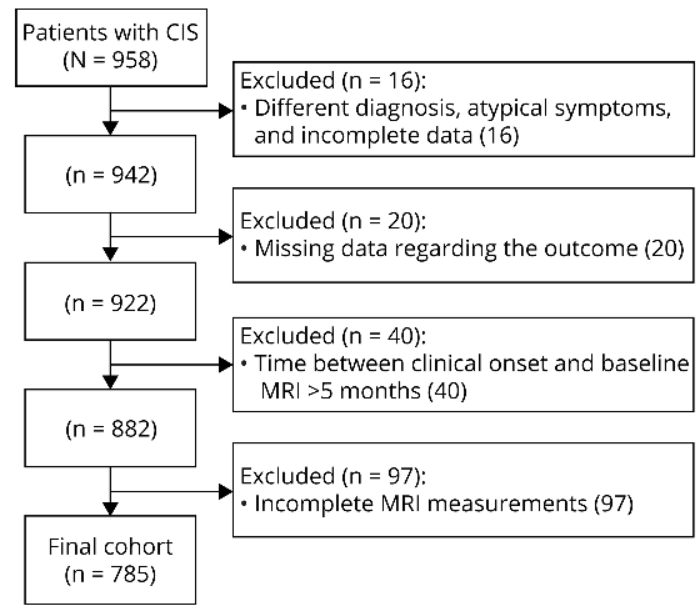




\section{Figure 2 Overall accuracy over timeand survival probability estimates of not developing}

CDMS according to the different sets of criteria investigated. (A) Overall accuracy of the 2010 McDonald (blue line) and 2017 McDonald criteria (red line), al so without OCBs assessment (gray line), determined by the AUC over time, up to 10 years, from disease onset, to the devel opment of CDMS, considering DIS only or DIS plus DIT. (b) Kaplan-Meier curves showing the survival probability estimates of not developing CDMS up to 10 years from di sease onset considering DIS only or DIS plus DIT according to the 2010 McDonald and 2017 McDonal d criteria, with or without OCBs assessment. aHRs with their corresponding 95\% Cl obtai ned from extended Cox regression models using time to CDMS as the outcome are al so shown.

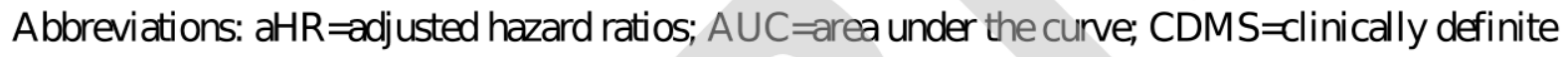
MS; $\mathrm{Cl}=$ confidence interval; DIS=dissemination in space; DIT=dissemination in time; OCBs=oligoclonal bands.

$*=$ adjusted for age, sex, centre, treatment, and type of onset. 


\section{A. Overall accuracy over time}

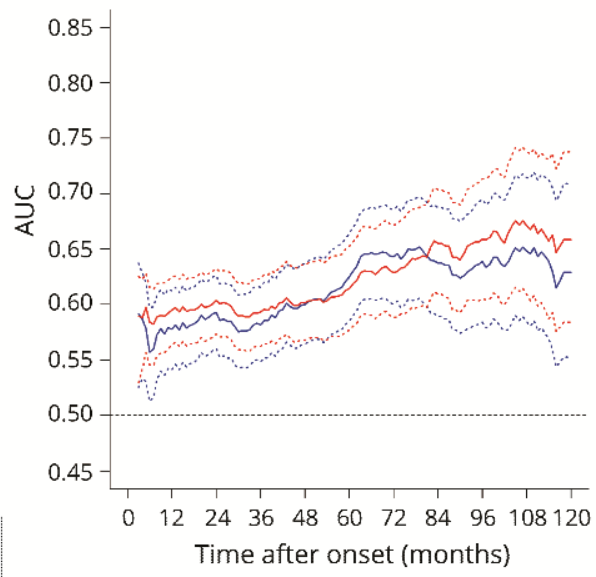

Number at risk:

Converters 0189268320339362370380386393400 Survivors $\begin{array}{llllllllllll}785 & 578 & 474 & 361 & 277 & 214 & 170 & 122 & 96 & 65 & 45\end{array}$ Censored $\quad 0 \quad 18 \quad 43 \quad 104 \quad 169209245 \quad 283 \quad 303 \quad 327340$

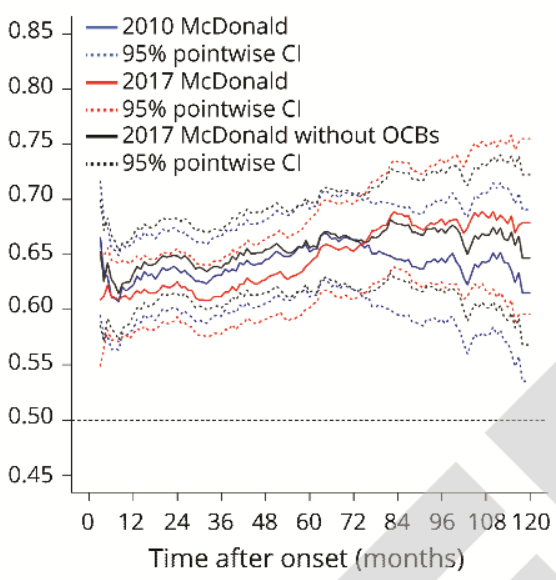

0 189268320339362370380386393400 $\begin{array}{lllllllllll}785 & 578 & 474 & 361 & 277 & 214 & 170 & 122 & 96 & 65 & 45\end{array}$

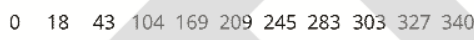

B. Survival probability estimates of not developing CDMS

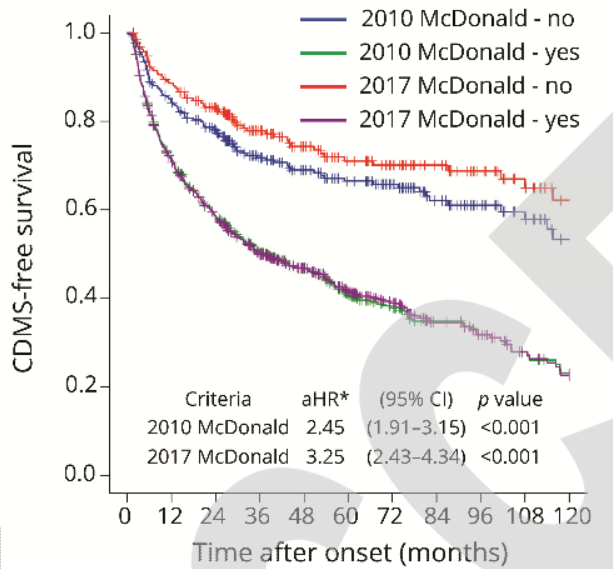

Number at risk:

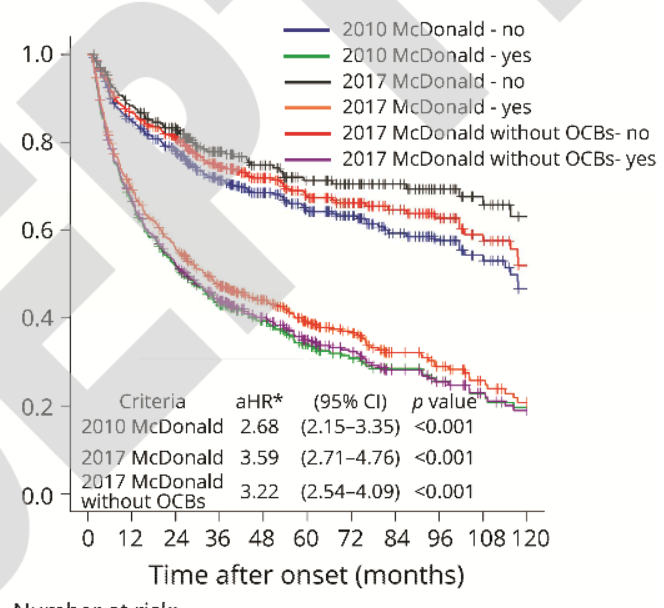

Number at risk:

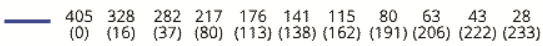

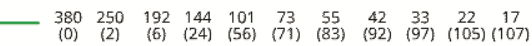

$\begin{array}{lllllllllll}252 & 216 & 187 & 136 & 114 & 95 & 79 & 64 & 49 & 34 & 23 \\ (0) & (7) & (24) & (64) & (81) & (95) & (190) & (125) & (1399) & (152) & (152)\end{array}$

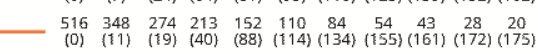

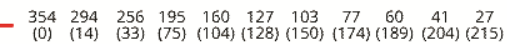

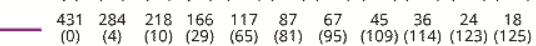


Figure 3. Overall accuracy over time according to the different sets of criteria investigated in CIS patients with different types of onset Overall accuracy of the 2010 McDonald (blue line) and 2017 McDonald criteria, with (red line), al so without OCBs assessment (gray line), determined by the AUC over time, up to 10 years, from disease onset, to the development of CDMS, considering DIS only, DIT only or DIS plus DIT in CIS patients with (A) optic neuritis, (B) brainstem/cerebellar syndrome, or (C) spinal cord syndrome as type of onset. Seetext for further details.

Abbreviations: $\mathrm{AUC}=$ area under the curve; $\mathrm{Cl}=$ confidence interval; DIS=di ssemination in space; DIT=dissemination in time; OCBs=oligoclonal bands. 


\section{A. Optic neuritis}

DIS only

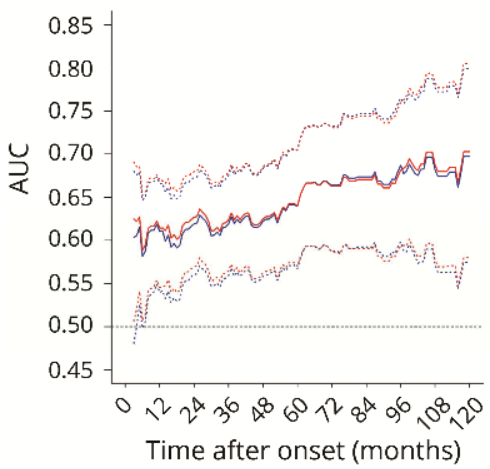

Number at risk:

Converters $\quad 0 \quad 5994115122130132135138142145$ Survivors $\quad 286222 \quad 17813310378 \quad 62 \quad 51 \quad 42 \quad 27 \quad 21$ $\begin{array}{llllllllllll}\text { Censored } & 0 & 5 & 14 & 38 & 61 & 78 & 92 & 100 & 106 & 117 & 120\end{array}$

B. Brainstem/cerebellar syndrome

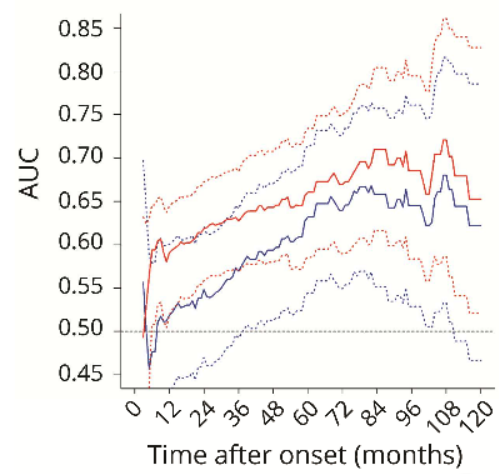

Number at risk:

Converters $\begin{array}{llllllllllll}0 & 39 & 51 & 62 & 65 & 71 & 72 & 75 & 75 & 77 & 77\end{array}$ Survivors $\quad \begin{array}{lllllllllll}169 & 127 & 108 & 82 & 64 & 51 & 44 & 31 & 23 & 14 & 11\end{array}$ $\begin{array}{llllllllllll}\text { Censored } & 0 & 3 & 10 & 25 & 40 & 47 & 53 & 63 & 71 & 78 & 81\end{array}$

\section{Spinal cord syndrome}

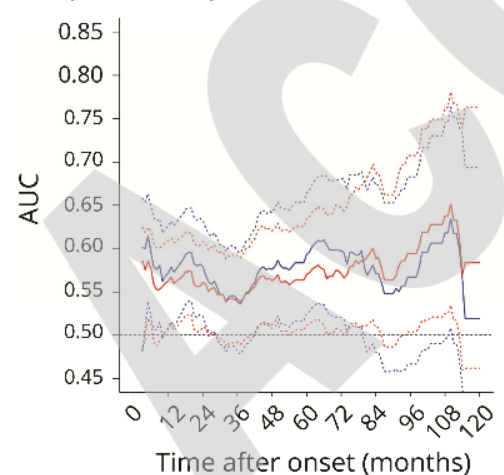

Number at risk:

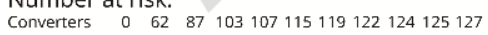

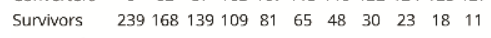
$\begin{array}{llllllllllll}\text { Censored } & 0 & 9 & 13 & 27 & 51 & 59 & 72 & 87 & 92 & 96 & 101\end{array}$
DIS plus DIT
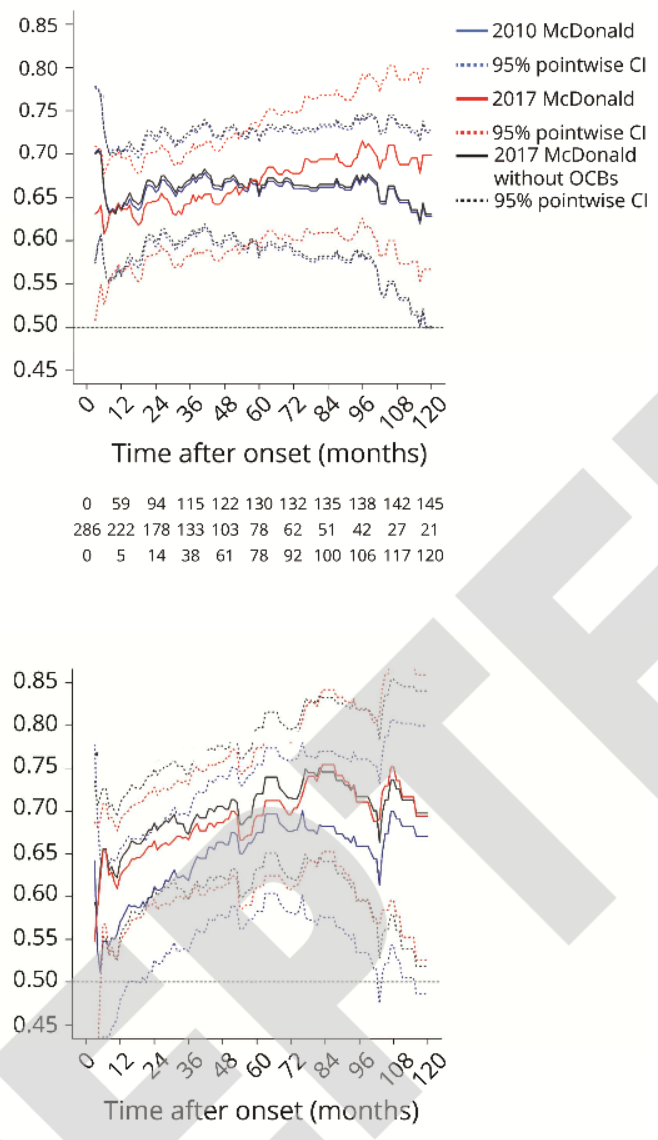

$\begin{array}{lllllllllll}0 & 39 & 51 & 62 & 65 & 71 & 72 & 75 & 75 & 77 & 77\end{array}$

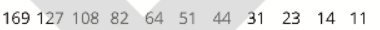
$\begin{array}{lllllllllll}0 & 3 & 10 & 25 & 40 & 47 & 53 & 63 & 71 & 78 & 81\end{array}$

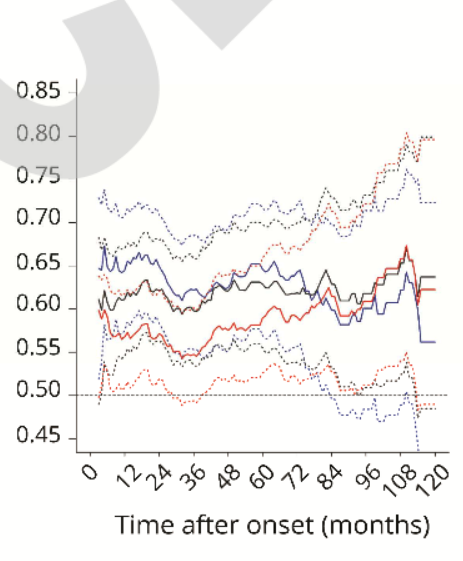

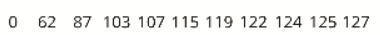

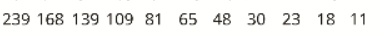
$\begin{array}{lllllllllll}0 & 9 & 13 & 27 & 51 & 59 & 72 & 87 & 92 & 96 & 101\end{array}$ 
Figure 4. Overall accuracy over time of DIS criteria according to age at onset and to 3 instead of 1 periventricular lesions. Overall accuracy of the 2010 McDonald (blueline), 2017 McDonald criteria, with 1 (red line) or 3 (gray line) periventricular lesions, determined by the AUC over time, up to 10 years, from disease onset, to the development of CDMS, considering DIS only in CIS patients aged ( $A$ ) $<25$ years, (B) 25-34 years, (C) 35-44 years or $\geq 45$ years at onset. See text for further details.

Abbreviations: $\mathrm{AUC}=$ area under the curve; $\mathrm{CDMS}=$ clinical ly definite $\mathrm{MS} ; \mathrm{Cl}=\mathrm{confidence} \mathrm{interval}$; DIS=dissemination in space.

A. $C \mid S:<25$ years $(n=155)$

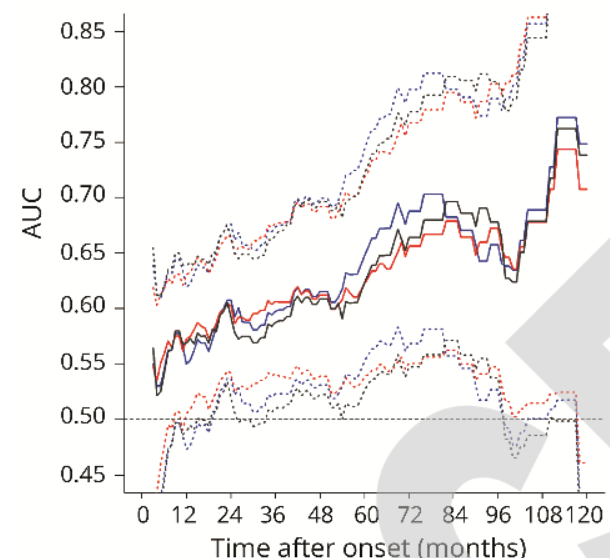

Number at risk:

$\begin{array}{llllllllllll}\text { Converters } & 0 & 49 & 71 & 81 & 83 & 90 & 91 & 93 & 93 & 94 & 95\end{array}$

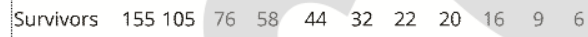
$\begin{array}{llllllllllll}\text { Censored } & 0 & 1 & 8 & 16 & 28 & 33 & 42 & 42 & 46 & 52 & 54\end{array}$

C. CIS: $35-44$ years $(n=210)$



Number at risk:

$\begin{array}{llllllllllll}\text { Converters } & 0 & 38 & 55 & 68 & 73 & 78 & 80 & 81 & 82 & 84 & 85\end{array}$

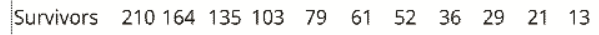

$\begin{array}{llllllllllll}\text { Censored } & 0 & 8 & 20 & 39 & 58 & 71 & 78 & 93 & 99 & 105 & 112\end{array}$

\section{B. CIS: $25-34$ years $(n=333)$}

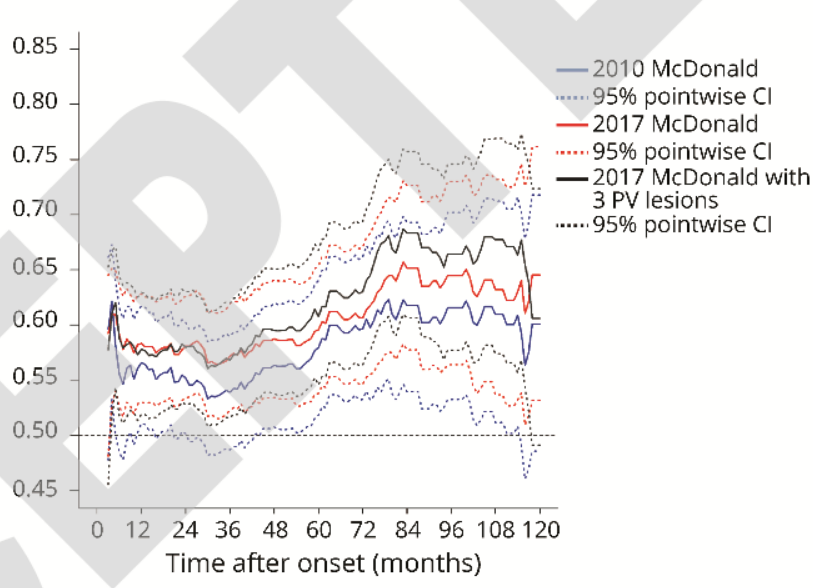

$\begin{array}{lllllllllll}0 & 86 & 119 & 142 & 154 & 163 & 168 & 175 & 179 & 182 & 187\end{array}$ $\begin{array}{lllllllllll}333 & 239 & 203 & 156 & 117 & 92 & 76 & 50 & 40 & 29 & 21\end{array}$ $\begin{array}{lllllllllll}0 & 8 & 11 & 35 & 62 & 78 & 89 & 108 & 114 & 122 & 125\end{array}$

D. $C I S: \geq 45$ years $(n=87)$

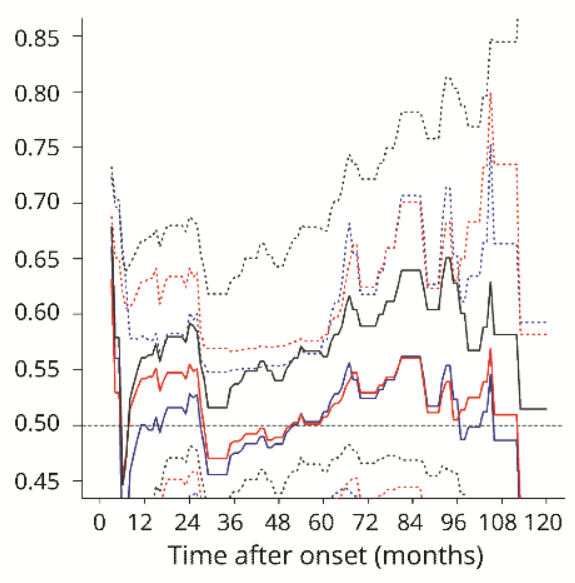

$\begin{array}{lllllllllll}0 & 16 & 23 & 29 & 29 & 31 & 31 & 31 & 32 & 33 & 33\end{array}$

$\begin{array}{lllllllllll}87 & 70 & 60 & 44 & 37 & 29 & 20 & 16 & 11 & 6 & 5\end{array}$

$\begin{array}{lllllllllll}0 & 1 & 4 & 14 & 21 & 27 & 36 & 40 & 44 & 48 & 49\end{array}$ 
Figure 5. Timeto MS diagnosis. Median time to MS diagnosis according to the different criteria investigated estimated using Kaplan-Meier survival curves: CDMS (green line), 2010 McDonald (blue line) and 2017 McDonald criteria (red line), al so without OCBs (gray line) assessment. Abbreviations: $\mathrm{CDMS}=$ clinically definite $\mathrm{MS} ; \mathrm{Cl}=$ confidence interval; $\mathrm{MS}=$ =multiple sclerosis; OCBs=oligoclonal bands.

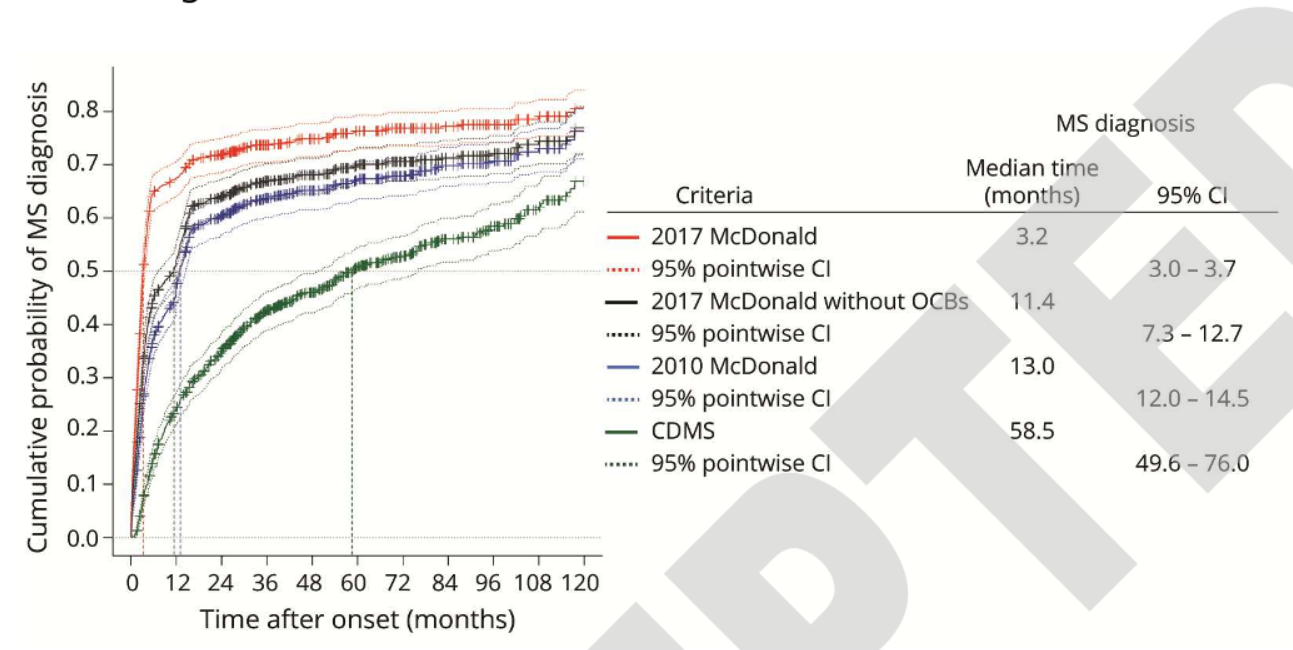

